\title{
SISTEMAS DE CAPTACIÓN E INNOVACIÓN EN LA FORMACIÓN DEL MILITAR BORBÓNICO. EDUCACIÓN PARA LA GUERRA ${ }^{1}$
}

\section{Recruitment and Innovation Systems in the Formation of the Bourbon Military. Education for War}

\author{
M. ${ }^{a}$ Dolores HERRERO FERNÁNDEZ-QUESADA \\ Universidad Complutense de Madrid \\ mariadhe@ucm.es
}

Fecha de recepción: 25/02/2020

Fecha de aceptación definitiva: 20/05/2020

\begin{abstract}
RESUMEN: El presente artículo trata de los sistemas de captación social y de educación militar en el XVIII, que partió del acceso discriminatorio y se articuló sobre dos procedimientos que coexistieron para educar a los cadetes. El modelo fue desigual promoviendo oficiales con instrucción diferente, destacando los de la academia de ingenieros de Barcelona; de artillería en Barcelona y Cádiz, y de Segovia. En el universo de la educación para la guerra, se integraron efímeros centros con innovadores planteamientos docentes; alguno focalizado premonitoriamente para todos los oficiales. La documentación oficial es definitiva para el análisis en clave de balance, desde la perspectiva del mito de las reformas militares borbónicas. Como aportación de interés y complementaria acreditamos que la educación militar entró en el debate social, dando voz a un contemporáneo, Cadalso, militar y escritor que en El buen militar a la violeta... aborda la formación del oficial y su representación social, con lo que cerramos el círculo del conocimiento sobre el modelo de educación para la guerra de los ejércitos borbónicos.
\end{abstract}

1. Este artículo se enmarca en el proyecto UCM-SANTANDER.PR87/19-22664. El estado empresario en la industria militar y su proyección atlántica (1750-1814), políticas, agentes y patrimonio arqueológico. Investigador Principal: María Dolores Herrero Fernández-Quesada. 
Palabras clave: formación militar; Academia de Bruselas; cadete de regimiento; colegios militares de Barcelona y Segovia; especialización científico-técnica; El buen militar a la violeta de Cadalso.

ABSTRACT: This article focused on the systems of social recruitment and military education in the XVIII, which started from discriminatory access and was articulated on two procedures that coexisted to educate the Cadets. The model was unequal promoting officers with different instruction, highlighting those of the academy of engineers in Barcelona, artillery in Barcelona and Cádiz, and Segovia. In the universe of education for war, ephemeral centers with innovative teaching approaches were integrated; some focused premonitory for all officers. The official documentation is final for the analysis in key of balance, from the perspective of the myth of the Bourbon reforms. As a contribution of interest and complementary we accredit that military education entered the social debate, giving voice to a contemporary, Cadalso, military and writer who in El buen militar a la violeta... addresses the training of the officer and his social representation, with what we close the circle of knowledge about the education model for the war of the Bourbon armies.

Key words: Military training; Academy of Brussels; Cadet of Regiment; Military Colleges of Barcelona and Segovia; specialization scientist and technical; El buen militar a la violeta of Cadalso.

\section{Precedentes y un Referente: la Academia de Bruselas de Medrano}

Las novedades en el sistema de reclutamiento de oficiales en los ejércitos borbónicos se nos presentan estrechamente vinculadas a la innovación en el sistema de formación militar, propio de un tiempo histórico acotado por la Revolución científica del siglo anterior y la Ilustración europea y española del XVIII. La reformulación del sistema de educación militar ilustrada se encuadra dentro de un prioritario proyecto de Estado de renovación integral del modelo militar de la Monarquía, en el marco general del reformismo borbónico. Con la llegada de Felipe V y, en breve, al tiempo que se combate en la guerra de Sucesión se inicia el proceso de reconversión de las estructuras militares sobre la base de la creación de los ejércitos permanentes ${ }^{2}$, materializado en la impresión de ordenanzas y reglamentos sucesivos

2. Herrero Fernández-Quesada, María Dolores. «El nuevo modelo de ejército en el contexto de la Guerra de Sucesión Española». En GARCía GARCía, Bernardo (coord.). En nombre de la paz. La Guerra de Sucesión Española y los Tratados de Madrid, Utrecht, Rastatt y Baden. 1713-1715. Madrid: Fundación Carlos de Amberes-SECC, 2013, pp. 91-106; Rodríguez HernáNDEZ, Antonio José. "El ejército que heredó Felipe V: su número y su composición humana». En Bernardo Ares, José Manuel de (coord.). La sucesión de la Monarquía Hispánica, 1665-1725. Córdoba: Universidad de Córdoba, 2009, pp. 265-301; y del mismo autor «¿Evolución o innovación? Los cambios técnico-tácticos en el armamento del ejército español durante el relevo dinástico: nuevas consideraciones». En HERRERO FERNÁNDEZ-QUESADA, 
M. ${ }^{a}$ DOLORES HERRERO FERNÁNDEZ-QUESADA

SISTEMAS DE CAPTACIÓN E INNOVACIÓN EN LA FORMACIÓN DEL MILITAR BORBÓNICO...

desde la publicación de las míticas Ordenanzas de Flandes $(1701,1702)^{3}$ hasta la edición final de las Ordenanzas de Carlos III en 17684, con las que se cerró la nueva constitución militar española y el modelo de los Reales Ejércitos permanentes y profesionalizados.

Entre las primeras reformas estructurales de la Nueva Planta Militar, analizaremos los cambios que iban asociados a los oficiales; su reclutamiento, que pasaría por la reformulación de las condiciones de acceso a los cuadros de mando; y, sin duda, lo que debían ser sus cimientos, la instrucción del oficial, en tránsito definitivo desde el empirismo en la praxis militar del pasado hacia una educación para la guerra apuntalada científica y técnicamente, imprescindible para enfrentarse a las formas de hacer la guerra y el progreso de las tácticas militares que se vislumbraban en un futuro ya próximo. El proceso de cambio de las estructuras militares, y singularmente del sistema de captación y formación de los oficiales borbónicos, se emprendió sosteniendo la guerra, y fue dinamizado por el Estado a partir de los mimbres heredados, manifiestamente obsoletos e inoperantes militarmente hablando. Para ilustrarlo cabe recordar dos ejemplos claros y bien documentados desde el inicio del conflicto bélico sucesorio, el mal estado de las fortificaciones y defensas fronterizas en Cataluña; y los problemas de la artillería que debía cubrir sus flancos y defensas en estado de "abandono» con cañones de diferentes calibres que no podían utilizarse por los servidores porque la munición no les correspondía, inequívoca señal de abandono, una artillería desactualizada e inservible para la defensa. De esta naturaleza fueron los detonantes de las primeras reformas militares, sin duda, espoleadas por el estado de guerra 5 . La herencia militar recibida se percibía negativamente también por la sociedad, pues se había generalizado una percepción social de la milicia devaluada. En lo que afecta al reclutamiento de la oficialidad y sus dificultades, la prueba del algodón estaría en la constatación del abandono progresivo de la carrera militar por aquellos que históricamente -por razones de linaje y función social cada vez más residual- habían nutrido los cuadros de mando de los ejércitos, con los resultados por todos conocidos. En este sentido, nuestra hipótesis responsabiliza de esta realidad a una suma de factores diversos, pero relacionados entre sí, en síntesis: evidente pérdida de valoración

María Dolores (coord.). Entre Marte y Minerva. Los Reales Ejércitos Borbónicos, del reformismo al mito. Cuadernos de Historia Moderna, 2016, 41, 2, pp. 273-294; ANDúJAR CASTILlo, Francisco. "El ejército de Felipe V: Estrategias y problemas de una reforma». En SERrano Martín, Eliseo (coord.). Felipe Vy su tiempo. Congreso Internacional. Zaragoza: Institución Fernando el Católico, 2004, pp. 661-682.

3. Archivo General Militar de Segovia [en adelante AGMS], sección 2. ${ }^{\text {a }}$, división 10. ${ }^{\text {, }}$, legajo 10. Ejemplares impresos, sueltos.

4. Ordenanzas de S.M. para el Régimen, disciplina, subordinación y servicios de sus Exércitos. Madrid; Oficina de Antonio Marín, 1768. 2 vols. Asimismo, se ha trabajado con la compilación de PORTugues, Joshep Antonio. Colección de Ordenanzas militares, sus innovaciones y aditamentos, dispuestos en diez tomos, con separación de clases. Madrid: Imprenta de Antonio Marín, 1764.

5. Archivo General de Simancas [en adelante AGS], Guerra Moderna, legajo 572 
social de la función militar; el deterioro progresivo de la imagen de los ejércitos y la milicia; y el peso del gasto militar en la sociedad, en un siglo marcado por la crisis generalizada. La convergencia en el tiempo de estos tres aspectos pudo ser el detonante del desinterés por ingresar en la milicia. Así, en el plano de las reformas militares, este fue el primer reto/obstáculo que había que salvar. De ahí que, en estrecha relación con ello, dentro de la arquitectura del nuevo modelo militar, nos ocuparemos de las coordenadas fijadas para el nuevo sistema de captación de oficiales y sus condiciones ya regladas; y en la reformulación del modelo de formación de los futuros oficiales. En este punto es importante recordar que la nueva planta militar y el proyecto de creación de los ejércitos permanentes iban a tener como marco institucional las nuevas estructuras políticas de la Monarquía, la Secretaría de Estado y el Despacho de Guerra ${ }^{6}$. De la misma forma que se gestionaron a través de la "Vía reservada" -línea directa establecida con el rey y sus ministros- las decisiones asociadas al nuevo sistema de formación para los oficiales, ya fuera en las unidades o en los colegios militares ${ }^{7}$. Sobre este renovado telón de fondo institucional, pasaremos a tratar los dos modelos coexistentes a lo largo del XVIII de educación militar: el Cadete de Regimiento -heredero de la figura del Cadete de Cuerpo que oficializó Carlos II en 1692, nuevamente el factor continuista de R. Hernández $-{ }^{8}$ que se formaba en aquellas unidades; y los Caballeros Cadetes que ingresaron en los nuevos colegios militares en régimen de internado, con planes de estudio que ya estaban en otra dimensión educativa, centros que se fueron abriendo sucesivamente, conformando el mapa -exponencialmente en aumento- de las academias militares que en las últimas décadas del siglo permiten hablar de la consolidación/institucionalización de la enseñanza militar ilustrada.

Sin embargo, cabe recordar aquí que en lo relativo a la educación militar no se partía de cero, hay una reconocida tradición academicista previa para la enseñanza de las matemáticas aplicadas a la milicia con la dinastía anterior ${ }^{9}$. Entre esos

6. La presencia de Felipe V en Italia durante la guerra de Sucesión aconsejó independizar las cuestiones bélicas y presupuestarias del resto de los asuntos administrativos encomendados a la secular Secretaría de Estado del Despacho Universal, que, desde el reinado de Felipe II, atendía todos los temas de gobierno. Después de Utrecht se reorganizaron los órganos del poder ejecutivo y el número de secretarías pasó de dos a cinco: Estado, Justicia, Guerra, Marina e Indias y Hacienda. La importancia de la Secretaría de Estado y del Despacho de Guerra fue en aumento.

7. Herrero FernándeZ-Quesada, María Dolores. «El Real Colegio de Artillería. De la fundación a la consolidación de un modelo de centro docente militar y científico-técnico». Revista Historia Militar. 250 aniversario del Real Colegio de Artillería. Instituto de Historia y Cultura Militar, 2014, 58, 1, pp. 73-133.

8. Rodríguez HERnández, Antonio José. «El ejército que heredó Felipe V: su número y su composición humana». En Bernardo ARes, José Manuel de (coord.). La sucesión de la Monarquía Hispánica, 1665-1725. Córdoba: Universidad de Córdoba, 2009, pp. 265-301.

9. Herrero Fernández-Quesada, María Dolores. Catálogo de la Biblioteca del Real Colegio de Artillería de Segovia. Fondos artilleros y de fortificación. Segovia: Academia de Artillería de Segovia, 1992; CÁmARA MuÑoz, Alicia (coord.). Los ingenieros militares de la monarquía hispánica en los siglos XVII y XVIII. Madrid: Ministerio de Defensa, 2005. 
M. ${ }^{a}$ DOLORES HERRERO FERNÁNDEZ-QUESADA

precedentes, uno, el más inmediato y cercano en el tiempo, fue determinante para configurar los parámetros del sistema de formación militar por el que optaron los Borbones y que diseñaron ad hoc ante la idiosincrasia territorial, política y militar de la Monarquía Hispánica. Nos referimos a la Academia Militar de Bruselas ${ }^{10}$, abierta en 1675, y lo que bien podemos calificar como el modelo novator de Sebastián Fernández de Medrano -secundado por el duque de Villahermosa como capitán general de Flandes-, en su innovador proyecto de centro docente militar para la formación de oficiales. Al apoyarlo, también se perseguía asegurarse una cantera de oficiales con alto nivel de especialización en fortificación. Hace tiempo constatamos que algunos de los militares de Carlos II se nos presentan en sus propuestas también como novatores y pioneros de una época posterior. Más aún se percibe en el ámbito en la formación de los ingenieros militares, al concienciarse tempranamente de la necesidad de una educación academicista reglada para ellos, pero también para oficiales que provenían de otras armas sin los conocimientos científico-técnicos para el servicio táctico operativo.

La importancia de la Academia de Bruselas requiere una investigación en profundidad porque en ella se encuentra el principal precedente y los cimientos de la tan celebrada enseñanza militar española de la Ilustración. En Bruselas, tan próximo el cronificado teatro de la guerra flamenco, los militares encontraron un laboratorio experimental que reportaba ininterrumpidamente lecciones aprendidas de la guerra. Esto, sumado al conocimiento de las tendencias europeas en el arte militar y en el progreso de la evolución técnica y táctica de la guerra cuya más compleja praxis reclamaba ya la formación en centros docentes especializados de los mandos, espolearon las inquietudes del emprendedor y autodidacta militar Sebastián Fernández de Medrano, de quien aún solo tenemos la síntesis biográfica de Rodríguez Villa ${ }^{11}$ a la que hay que seguir recurriendo, también porque la documentación es pacata a la hora de informar sobre el centro, la trayectoria y la obra del militar. En una época de hegemonía francesa y de las formas de fortificación a lo Vauban -reputado ingeniero francés al servicio de Luis XIV- abaluartadas y especializadas en las técnicas de ataque y defensa de plazas (como reza el título de uno de sus más importantes tratados) hay que poner en valor la aportación de este español -con claro perfil novator- y de sus formas pedagógicas para transmitir y enseñar el arte de fortificar, la artillería, la ciencia militar en general, sin duda punto de partida del posterior proceso de institucionalización de la enseñanza militar. La Monarquía Hispánica mantenía un escenario permanente de guerra en Flandes y allí, donde más necesario era, Sebastián Fernández de Medrano fundó y

10. CAPEl SÁEz, Horacio; SÁnCHEZ, Joan Eugeni y MonCADA, Omar. De Palas a Minerva: la formación científica y la estructura institucional de los ingenieros militares en el siglo XVIII. Madrid: CSIC, 1988; Clonard, Conde de. Memoria histórica de las Escuelas Militares, 1847; Vigón Suero-Díaz, Jorge. Historia de la Artillería Española. Madrid: CSIC, 1947. 3 tomos.

11. Rodríguez Villa, Antonio. Noticia biográfica de Don Sebastián Fernández de Medrano (1646-1705). Madrid, 1885. 
fue director de la Academia Militar de Bruselas, donde tras la conformación de un inédito plan de estudios y contenidos, partiendo de las matemáticas y geometría (fundamentos del alto nivel allí impartidos), se formaba a los alumnos en las disciplinas militares más técnicas, fortificación y artillería ${ }^{12}$. Pero más aún, Medrano también fue pionero de lo que después ha sido reconocido como un gran logro ilustrado y una herramienta pedagógica innovadora: los manuales, tratados o textos militares redactados específicamente para los alumnos que recibían formación militar en aquel centro ${ }^{13}$. Una prueba fehaciente se tiene en los diferentes tratados editados en Bruselas para el estudio en su academia, siendo el autor de muchos de ellos. Históricamente toda la tratadística clásica de fortificación y artillería trabajó en el perfeccionamiento de las técnicas tanto para atacar como para defender, la fundición de los materiales y las técnicas de construcción de fortificaciones definitivamente empleadas, al igual que Medrano en sus obras incluyó capítulos en los que pone de manifiesto la implicación secular de los artilleros en las actividades industriales, en la fabricación no solo de los materiales, pólvoras y municiones, sino de armas en general. Esto se percibe con más intensidad en el siglo XVII, centuria en la que el abastecimiento a la Corona se hacía mediante los sistemas de asientos, aunque ya se notaba la intervención de gente de artillería en los diferentes procesos de fabricación, con el objetivo de formar y promover aquellos perfiles de oficiales que rezaban en el título de sus obras El arquitecto perfecto en el arte militar o El perfecto artillero por poner tan solo dos ilustrativos ejemplos ${ }^{14}$. Desde las grandes obras decimonónicas de historia militar, como el clásico Clonard $^{15}$, no se ha dejado de repetir en publicaciones posteriores -sin contribuciones añadidas- la organización de aquella academia de Bruselas, lo que pone de manifiesto cómo sentaron precedente en el ideario docente y planes de estudios, partiendo en el primer curso de lo general en el arte militar a lo particular en los siguientes; y en la metodología académica entre los apuntes manuscritos evaluables y el

12. Diccionario biográfico de la Real Academia de la Historia. Voz Sebastián Fernández de Medrano. http://dbe.rah.es/biografias/9406/sebastian-fernandez-de-medrano.

13. FERnÁNDEZ DE MEDRANo, Sebastián. Memorias militares en que solo se trata del manejo de la Artillería, sus diferencias, conocimientos de metales y refuerzos, y puntos más convenientes para la práctica, uso y advertencia de los artilleros. Madrid: Imprenta Mateo Espinosa y Arteaga, 1671; El práctico artillero que contiene tres tratados. En el primero se declaran las piezas de cada género, y sus diferencias, y se enseña el modo de obrar en las cucharas, y Afustes, y el designio de las baterías. En el segundo se trata del manejo del cañón, con algunas advertencias sobre sus alcances. Y el en tercero se trata en breve del puesto de cada oficial, y otras advertencias. Bruselas: Imprenta Francisco Foppens, 1680; El arquitecto perfecto en el arte militar. Dividido en cinco libros. El 1. ${ }^{\circ}$ contiene la fortificación regular e irregular a la Moderna. El II la especulación sobre cada de sus partes. El III la fábrica de Quarteles, almazenes a prueva de Bomba, y de toda suerte de murallas tanto en tierra firme como en el agua. El IV la defensa y ataque de una plaza según el nuevo modo de guerrear. La V la Geometría. Trigonometría, Cálculos, Regla, proporción, etc. Amberes: Imprenta Henrico y Cornelio Verdussen, 1708.

14. Del primero se ha consultado la edición publicada en Amberes en 1708; y del segundo la impresa en Bruselas en 1680 y primera edición de la obra.

15. Clonard, Conde de. Memoria histórica de las Escuelas Militares, 1847. 
M. ${ }^{a}$ DOLORES HERRERO FERNÁNDEZ-QUESADA

SISTEMAS DE CAPTACIÓN E INNOVACIÓN EN LA FORMACIÓN DEL MILITAR BORBÓNICO...

estudio de los tratados impresos para la enseñanza militar en el centro. Por nuestra parte, se ha podido constatar en estudio comparado de esa planificación docente inspirada por Medrano y la estructura de los planes de estudios de las academias y colegios de los Cuerpos Facultativos.

\section{FELIPE V: CAPTACIÓN SOCIAL Y FORMACIÓN DE OFICIALES PARA UN EJÉRCITO PROFESIONALIZADO}

En el diseño y puesta en marcha del nuevo modelo militar y sus sucesivos cambios estructurales, uno de los efectos reformadores del conflicto sucesorio fue precisamente la nueva política de formación de la oficialidad y captación de jóvenes para lo que ya se planteaba como una carrera profesional, asociada a una innovadora conceptualización de la formación de los cuadros de mando dieciochescos que tuvo como seña de identidad la necesidad de conocimientos y disciplinas teóricas por parte de los militares para poder desempeñar con solvencia sus destinos castrenses. Por tanto, disminución de la carga docente empírica y aumento de los contenidos y disciplinas científico-técnicas, maridaje recurrente en los colegios militares que se fueron fundando a lo largo de la centuria. En este artículo transitaremos por el devenir evolutivo de la educación para la guerra, sus bases y sus nuevas formas a través de los reinados de los sucesivos monarcas de la centuria. Las experiencias previas europeas, y, especialmente, francesas, pusieron de manifiesto que una de las claves fundamentales para el éxito del nuevo modelo militar permanente y profesional, cimentado sobre la institucionalización de los reales ejércitos, era conseguir un perfil/ prototipo de oficial capaz de pilotar el arranque y evolución de ese nuevo ejército al servicio de la Monarquía, pero acordes con el tiempo y el siglo que les tocó vivir. En primer lugar, abordaremos el nuevo sistema de captación de futuros oficiales y las condiciones que debían cumplir los aspirantes; aspecto que estuvo estrechamente ligado al nuevo modelo de educación militar. En todo este proceso de cambio y tránsito del modelo militar de los Austrias al borbónico, era imprescindible dar con las herramientas para subvertir la devaluada imagen social de la milicia y conseguir el cambio de percepción de la institución militar por parte de la sociedad. En este sentido se enfocaron las medidas encaminadas a la renovación del sistema de captación de oficiales. Para ello, en el reclutamiento -siempre voluntario- de los futuros mandos, la elección del yacimiento social, su origen, iba a ser determinante; y, sin duda, muy acertado el soporte central del discurso: reconciliar a la nobleza con el Ejército, intentando motivar a la juventud noble para integrarse en la milicia al servicio de la Monarquía ${ }^{16}$, presentando esta opción como atractivo proyecto de futuro,

16. Cepeda Gómez, José. "Prólogo». En Herrero Fernández-Quesada, María Dolores. La enseñanza militar ilustrada. El Real Colegio de Artillería de Segovia. Segovia: BCA, 1990. CEPEDA GÓmEZ, José. "Servir al Rey y servir a la nación: ilustrados, liberales y el deber militar». Cuadernos de Historia Moderna, 1995, 16, pp. 139-146. 
como privilegio únicamente reservado para ellos por el rey. Este sería entonces el primer paso del proceso de renovación de la educación militar borbónica, captar a las nuevas generaciones del estamento nobiliario. Definida y acotada la procedencia social, el segundo paso era diseñar un sistema docente militar para aquellos jóvenes nobles y reportarles una ilustrada formación militar y científico-técnica, tan necesaria ya para el ejercicio de la carrera de las armas, cerrando así el círculo de la renovada imagen de la milicia que se quería proyectar: origen social privilegiado y formación de élite como soportes del alto perfil de oficial al que se aspiraba. Hay que incidir en la relevancia de estos dos aspectos por su proyección en la trayectoria de los militares. Por un lado, fue decisiva la elección del yacimiento social, del grupo social donde se iba a tirar la caña por parte de la Monarquía para formar el cuerpo de oficiales; pero también, singularmente, en el planteamiento, en la construcción del mencionado discurso de captación para lograr resultados positivos en el reclutamiento de los jóvenes nobles, nuevamente interesados por la milicia, pues la respuesta fue altamente positiva. Así, la oferta de poder seguir la carrera de las armas de una manera profesionalizada se hizo a las nuevas generaciones de la nobleza, cuya calidad iba a pasar a ser seña de identidad del perfil del militar ilustrado. De esta política de seducción y comunicación de la política militar enfocada hacia aquellos jóvenes, es justo reconocer que el discurso de marketing fue lo más inteligente. El mensaje principal enganchaba, pues se les estaba reservando a ellos como privilegio acceder a los mandos de los reales ejércitos, solo ellos podrían optar al servicio de las armas de S. M. excluyendo explícitamente a jóvenes de otros grupos sociales que no podrían competir, y, definida la misión como servidores del rey, resultó ser que los incentivos de este proyecto funcionaron.

Este fue un meditado criterio, porque se trataba de situar en los cuadros de mandos de los nuevos ejércitos permanentes y unidades a oficiales de origen acreditado que, después, serían lo mejor formados posible para llevar adelante el éxito del modelo. No pasa desapercibido que, de esta forma, se reglaba con toda naturalidad un principio de desigualdad social que a nadie pareció chirriar ni siquiera a las élites ilustradas de poder y sociales que tenían por bandera la consecución del progreso generalizado para el reino, desigualdad que solo se revirtió en el proceso de cambio de este modelo militar que diseñaron los diputados constituyentes de Cádiz en sus trabajos de organización del ejército, ya nacional, tomándose como primera medida la supresión de la presentación de pruebas de nobleza o calidad para ingresar en el ejército ${ }^{17}$. Todo parecían ventajas, porque el rédito para la Monarquía fue importante, empezando por que así se aseguraron

17. Herrero Fernández-Quesada, María Dolores. "La presencia militar en las Cortes de Cádiz". En Frieyro de LaRA, Beatriz. España Contemporánea. Granada: Universidad de Granada-MADOC, 2009, pp. 421-450. 
la fidelización de la oficialidad, deudora del privilegio real ${ }^{18}$. Captación social acertada y asegurada, la educación y la instrucción militar de aquellos que debían empatizar y empatizaron con este modelo ilustrado de progreso, dentro del proyecto de Estado del reformismo borbónico, estuvieron planteadas desde el minuto uno sobre coordenadas académicas inéditas hasta entonces marcadas por los objetivos de la política reformista, que se irán visibilizando a lo largo del siglo y que en breve fueron especialmente constatadas a través de los éxitos militares y científico-técnicos de esta institución no solo en el ámbito castrense, sino proyectando su conocimiento y alto perfil, sus luces a otros ámbitos, científico, técnico, político, cultural... siempre al servicio de la Monarquía ${ }^{19}$. Hasta aquí el análisis y descripción de lo reglado, de lo prescrito en las ordenanzas, la narrativa oficial con la que se toma contacto a través de la documentación oficial. Sin embargo, la investigación en un importante número de expedientes personales de oficiales del XVIII lleva a la localización de informaciones dispersas que conducen a conclusiones abiertas a matices, y a colegir que efectivamente hubo oficiales nobles acreditados en su «calidad». Pero en sucesivos trabajos prosopográficos, mayoritariamente, nos hemos enfrentado a hojas de servicio en las que en el apartado "calidad" simplemente figuraba que "la tiene» o como "notoria», sin informaciones añadidas. Es más, al trabajar esta documentación personal, parece claro que no solo los jóvenes de dentro del estamento nobiliario en sus diferentes estratos estaban interesados por ingresar en la milicia, sino que eran otros y sus familias (muy bien posicionadas social y económicamente) quienes iban llegando al alfoz del estamento desde los puestos de poder y siguiendo dinámicas familiares de movilidad social, atraídos por el ofrecimiento de la Monarquía de pasar a formar parte de sus cuadros de mando profesionalmente, en especial en la segunda mitad del siglo, miembros de grupos sociales emergentes que aspiraron a la carrera de las armas, profesión que, por cierto, además, les proporcionaría un modus vivendi, dedicándose a la milicia de por vida ${ }^{20}$. Luego en la prospección en torno a la procedencia

18. Calvo Maturana, Antonio. "La oficialidad del ejército y la marina borbónicos: reformismo, fidelidad e identidad (1750-1808)». En HERRERO FERnÁnDEZ-QuESADA, María Dolores (coord.). Entre Marte y Minerva. Los Reales Ejércitos Borbónicos, del reformismo al mito. Cuadernos de Historia Moderna, 2016, 41, 2, pp. 467-495.

19. Una información más amplia sobre los réditos que el sistema de captación y formación de los oficiales aportó a la Monarquía en HERrero FERnÁndeZ-Quesada, María Dolores. «Educando a Marte. Rentabilidad de la innovación docente militar y versatilidad profesional». En HERRERO FERnÁNDEZ-QuESADA, María Dolores (coord.). Entre Marte y Minerva. Los Reales Ejércitos Borbónicos, del reformismo al mito. Cuadernos de Historia Moderna, 2016, 41, 2, pp. 391-424.

20. ANDújar CASTIllo, Francisco. «El ejército borbónico en el último tercio del siglo XVIII: permeabilidad social en una institución nobiliaria». Chronica Nova, 2014, 40, pp. 131-154; Imízcoz BEunZA, José María. "Militares ilustrados. Parentesco, amistad y afinidades políticas en la formación de las élites estatales en el siglo XVIII. En García HurTado, Manuel Reyes (ed.). Soldados de la Ilustración. El Ejército español en el siglo XVIII. La Coruña: Universidad de La Coruña, 2012, pp. 165-214; GARCíA HuRTADO, Manuel Reyes. "Formación militar de infantería y caballería en las academias del XVIII". En 
social de los oficiales del XVIII se constata la diversidad, derivada de la silente dinámica de permeabilidad social, emergiendo desigualdades notables en la calidad de la oficialidad. También con respecto a la calidad, podría afirmarse lo mismo sobre sus esposas, más aún con ocasión de la creación por Carlos III del Monte Pío Militar en 1764 para cubrir los imponderables de la viudez o la orfandad ${ }^{21}$. Desde su casamiento pasaban a acogerse al fuero militar ${ }^{22}$; y para contraer matrimonio con oficial se regló un procedimiento para presentar documentación acreditativa de los orígenes sociales y familiares de las aspirantes a esposas, cuando menos de dos generaciones anteriores ${ }^{23}$. Grandeza, pero proporcionalmente, las menos ${ }^{24}$.

En suma, y en el ámbito temático que nos ocupa, la educación para la guerra, se definieron y persiguieron dos objetivos claros: jóvenes de la nobleza para nutrir los cuadros de mando de los ejércitos borbónicos y el diseño de un nuevo sistema de formación militar práctica para unos oficiales que debían estar al tanto del devenir y progreso de las nuevas tácticas técnicas y sistemas de armas del XVIII, cuyos oficiales -que formaron una élite profesional y social compacta dinámica e interactiva- a corto medio y largo plazo resultaron ser una valiosa herramienta en manos de la Monarquía para la implementación de las políticas ilustradas. Para regular el acceso a la milicia y partir de aquí, todo se puso negro sobre blanco. Es decir, se legisló. Se promulgaron ordenanzas y reglamentos e instrucciones con las condiciones de acceso para integrar ese nuevo y elitista tejido profesional de la oficialidad borbónica, explicitando la obligatoriedad y naturaleza de la documentación acreditativa requerida, y que debía pasar por los filtros de la autoridad militar. De esta forma, la nueva planta militar de Felipe V se ocupó de controlar y seleccionar el origen social de quienes ingresaran en la carrera de las armas ya totalmente profesionalizada. La estrategia de atracción de la nobleza a la oficialidad

Imízcoz BeunZa, José María y Chaparro, Álvaro (eds.). Educación, redes y producción de élites en el siglo XVIII. Madrid: Sílex, 2013. 1761.

21. Reglamento de la fundación y establecimiento del Monte Pío Militar. Madrid: Imprenta Real,

22. AndúJar CASTillo, Francisco. "El fuero militar en el siglo XVIII. Un estatuto de privilegio». Chronica Nova, 1996, 23, pp. 11-31.

23. Los expedientes matrimoniales de oficiales y las testamentarías de sus mujeres, también aforadas, constituyen un excepcional yacimiento documental. Por nuestra parte y a partir de una cata realizada sobre expedientes matrimoniales y testamentarías, hemos trabajado en ello en HERRERO FERnÁNDEZ-Quesada, María Dolores. «¿Una aguja en un pajar? En torno a un caso de divorcio en los archivos militares». En HERnÁNDEZ SANDOICA, Elena. Espacio público y espacio privado, miradas desde el sexo y el género. Madrid: Abada, 2016, pp. 319-356 y "Matrimonio con militar. Procedimientos, excepciones a la norma y contenciosos a finales del Antiguo Régimen». En CAPEL MARTínez, Rosa María. La voz de las mujeres en el espacio público (siglos XVII-XX). Madrid: Abada. OCERIN y GARCía DE Llamera, Enrique. Índice de los Expedientes Matrimoniales de Militares y Marinos que se conservan en el Archivo General Militar (1761-1865). Madrid: CSIC, Instituto Jerónimo Zurita, 1959. 2 volúmenes.

24. HerRERo FERnÁNDEZ-Quesada, María Dolores. «La investigación en historia militar de la Edad Moderna y sus fuentes. El Archivo General Militar de Segovia, Decano de los archivos militares españoles». Cuadernos de Historia Moderna, 2012, 38, pp. 165-214. 
borbónica como privilegio, elegidos por el rey para que solo ellos le sirvieran como oficiales y mandos en los reales ejércitos, ha sido ponderada sistemáticamente como un ardid destinado a mejorar la imagen del ejército y la milicia en la sociedad, anteriormente sumida en un proceso de descrédito e infravaloración social. Sin embargo, como ya hemos mencionado, el análisis de la voluminosa documentación acreditativa del origen, presentada por los jóvenes nobles aspirantes a seguir la carrera de las armas, invita al balance y apunta a la desmitificación. El trabajo prosopográfico a partir de las hojas de servicio y expedientes personales de los oficiales confirma que todos ellos tenían la calidad, pero sin duda, a día de hoy, hay que ampliar la perspectiva investigadora y hay que centrarla en la determinación del rango dentro del estamento, al presentarse una mayoría de militares con el origen nobiliario reconocido, pero mayoritariamente procedentes de la base del estamento, lo que nos llevará a analizar desde nuevas perspectivas la respuesta del colectivo nobiliario ante la propuesta real, singularmente si la política militar de Felipe $\mathrm{V}$ con respecto a la integración de la nobleza en los cuadros de mando de su ejército cubrió objetivos y en qué medida. En principio las expectativas fueron altas, pues, recién acabada la guerra, se esperaba una respuesta cuantitativamente importante de la alta nobleza y nobleza titulada que, sin embargo, acudió minoritariamente a la llamada, salvo en los Cuerpos de la Casa Real que obviamos por su especificidad ${ }^{25}$. Estudiando el grueso de la oficialidad del ejército, sus armas y cuerpos, y como avance se presume y constata que la política de captación fracasó entre las familias de los rangos más altos, entre la nobleza titulada; y paralelamente se constata cuantitativamente que en el ejército ingresaron mayoritariamente jóvenes de la baja nobleza que cursaron la carrera de las armas de forma profesional, lo que, de paso, resolvía económicamente su vida. Así, concluyendo que fueron mayoría los militares con calidad contrastada, pero de rango bajo, se entiende que la milicia deviniera en un grupo social emergente, identificado y motivado con el reformismo militar borbónico desde donde podrían y pudieron ascender política y socialmente. Avanzado el siglo se consolidarán como élite social y grupo de poder dinámico ${ }^{26}$. Hace ya muchos años historiadores como Domínguez Ortiz han reflexionado además sobre la trascendencia

25. ANDÚjar Castillo, Francisco. "Élites de poder militar: las guardias reales en el siglo XVIII". En Dedieu, Jean-Pierre; Castellano, Juan Luis y LóPez-Cordón, María Victoria. La pluma, la mitra y la espada: estudios de historia institucional en la Edad Moderna. Madrid: Marcial Pons, 2000, pp. 65-94; GLESENER, Thomas. "Reformar el corporativismo militar: la acción política del duque de Montemar como ministro de guerra (1737-1741)». En HERRERO FERNÁNDEZ-QuESADA, María Dolores (coord.). Entre Marte y Minerva. Los Reales Ejércitos Borbónicos, del reformismo al mito. Cuadernos de Historia Moderna, 2016, 41, 2, pp. 313-335.

26. HerRero FERnÁndez-Quesada, María Dolores (coord.). Entre Marte y Minerva. Los Reales Ejércitos Borbónicos, del reformismo al mito. Cuadernos de Historia Moderna, 2016, 41, 2; IMízCOZ Beunza, José María y Chaparro, Álvaro (eds.). Educación, redes y producción de élites en el siglo XVIII. Madrid: Sílex, 2013. 
M. ${ }^{a}$ DOLORES HERRERO FERNÁNDEZ-QUESADA

SISTEMAS DE CAPTACIÓN E INNOVACIÓN EN LA FORMACIÓN DEL MILITAR BORBÓNICO...

de esta política militar borbónica para concluir que, a medio plazo, esta política de selección y formación de los oficiales se sustanció en el nacimiento de la institución militar como clase social, con un acendrado espíritu corporativista y, fundamental, con la conciencia de tener unos intereses comunes ${ }^{27}$. Grupo social compacto por la argamasa que formaban los intereses comunes, profesionales y sociales, que, en un breve espacio de tiempo, deviene en élite social y de poder ${ }^{28}$.

\subsection{Coexistencia de dos sistemas de educación para la guerra}

Sobre estas bases y en esta línea de trabajo ya descrita, en el reinado de Felipe $\mathrm{V}$ se consolidaron dos sistemas distintos de formación militar para los oficiales de un mismo ejército. La nueva dinastía compatibilizando con el desarrollo de la guerra, dentro del nuevo modelo militar en construcción, optó por dos sistemas coexistentes de formación para los oficiales, según el arma o cuerpo donde fueran a servir, pero siempre con unas mismas condiciones de acceso, requeridas a todos por igual para crear ese colectivo profesional y social homogéneo, y respetado, al que aspiraba la Monarquía: los Cadetes de Regimiento en las unidades o los que ingresaron en los colegios militares de nueva creación. A partir de aquí evocaremos cuál fue el modus operandi, el procedimiento de selección de los aspirantes a oficial y las condiciones para el acceso a los ejércitos borbónicos. En esto, de nuevo, encontramos un punto de entronque con el pasado más reciente que profundiza en la continuidad defendida por Rodríguez Hernández. Desde 1692, reinando Carlos II, se cambió la forma de ingreso al periodo de instrucción, creándose la figura del llamado "Cadete de Cuerpo", clase y vía reservada a la nobleza "para poder recibir en las unidades la instrucción necesaria». Felipe V reglamentó la modalidad francesa de los Cadetes de Cuerpo en las nuevas unidades, los regimientos. Así, las primeras ordenanzas borbónicas, publicadas en las dos décadas iniciales del siglo XVIII, se ocuparon de los empleos militares y su nueva nomenclatura, y presentan como innovación la creación de la clase de Cadetes de Cuerpo como única vía de ingreso para el Cuerpo de Oficiales. Esta importante medida se implantó a partir de la Ordenanza de 1704 que regulaba el ingreso de Cadetes en la Milicia Provincial, siendo ya en la Ordenanza de 1712 cuando se reglamentó su inserción en los Regimientos de Infantería, prescribiéndose lo mismo en la Ordenanza de 1722 para la Caballería y los Dragones. Finalmente, las Ordenanzas de 1728 generalizaron el modelo y proveyeron de una plaza de Cadete a cada Compañía, a la que solo podían optar los títulos del Reino, sus hijos

27. Domínguez Ortiz, Antonio. La sociedad española en el siglo XVIII. Madrid, 1995.

28. Imízcoz Beunza, José María. "Militares ilustrados. Parentesco, amistad y afinidades políticas en la formación de las élites estatales en el siglo XVIII. En García HurTado, Manuel Reyes (ed.). Soldados de la Ilustración. El Ejército español en el siglo XVIII. La Coruña: Universidad de La Coruña, 2012, pp. 165-214. 
M. ${ }^{a}$ DOLORES HERRERO FERNÁNDEZ-QUESADA

SISTEMAS DE CAPTACIÓN E INNOVACIÓN EN LA FORMACIÓN DEL MILITAR BORBÓNICO...

y hermanos, los Caballeros de las Órdenes Militares y los hidalgos de sangre con ejecutoria de nobleza ${ }^{29}$, literalmente, los «hijodalgo notorio, según las leyes de mis Reynos, debiendo hacer constar esta calidad formalmente con instrumentos comprobados y justificativos ${ }^{30}$.

El planteamiento del sistema de formación variaba: en Infantería y Caballería (el grueso del ejercito) se optó por el Cadete de Regimiento; y en los Cuerpos Facultativos (Artillería e Ingenieros), minoritarios, por la formación en colegios militares. Así encontramos que las unidades de los ejércitos, los nuevos regimientos, se convierten en centros de instrucción militar teórico-práctica para los futuros oficiales, inevitablemente estamos entonces ante un proceso formativo de una mayor carga empírica de esas enseñanzas, sujeto a variables fluctuantes que determinarían resultados dispares en la formación de la oficialidad como el nivel del cadete, lo que traían sabido de sus casas o lo que estudiaron en colegios de jesuitas, y muchos, eso sí, de instituciones docentes ilustradas como los procedentes del Seminario de Nobles ${ }^{31}$ o el Seminario de Vergara ${ }^{32}$; la formación del capitán de Cadetes, su instructor, desigual también, al igual que su vocación docente, no todos tenían interés o valían para ello; y finalmente el devenir de la unidad cuya existencia se justificaba por encima de todo para combatir en guerra y que, ante esa eventualidad, era prioritario, por lo que cualquier contingencia bélica interrumpía la continuidad en la educación militar del Cadete. Para las dos Armas Sabias, Ingenieros y Artillería, numéricamente inferiores, la formación de sus oficiales siempre se planteó desde la premisa de la necesidad inexcusable de abrir centros docentes específicos por la evidente carga científico-técnica de la ingeniería militar y de la artillería como sistemas de armas puntero: los colegios o academias. Ingenieros en Barcelona; Artillería en Cádiz y Barcelona, y después Segovia, pero ya con Carlos III. Esta diferencia en el sistema de enseñanza siempre fue determinante a la hora de ponderar los resultados, a favor de este segundo sistema basado en la academia. Entre Felipe V y Carlos III se consolidó un modelo de enseñanza militar sustanciado en la fundación de centros docentes, Reales Colegios en los que transcurría el periodo de formación de los Caballeros Cadetes que acuñaron un perfil de oficial, del militar español del XVIII, muy específico, con unos parámetros excepcionales hasta

29. Herrero FERnÁNDEZ-Quesada, María Dolores. "La artillería de Ordenanza; contribución al estudio de las reformas militares en el reinado de Felipe V». Memorial de Artillería, 1993, 2, pp. 81-86.

30. Instrucción de lo que parece conveniente se mande observar, si fuere del agrado de S.M. acerca de las circunstancias que deben concurrir en la admisión de los individuos para la Compañia de Caballeros Cadetes del Real Colegio de Artillería, destinada en el Departamento de Segovia, 1763. Estas condiciones así redactadas aparecen en el resto de reglamentos y ordenanzas que durante el siglo XVIII reglaron el ingreso de los Caballeros Cadetes a las academias militares.

31. Andújar Castillo, Francisco. "El Seminario de Nobles de Madrid en el siglo XVIII. Un estudio social». Cuadernos de Historia Moderna, Anejos, 2004, 3, pp. 201-225.

32. Chaparro SAINZ, Álvaro. "La formación de las élites ilustradas vascas: el Real Seminario de Vergara». En Imízcoz Beunza, José María y Chaparro, Álvaro (eds.). Educación, redes y producción de élites en el siglo XVIII. Madrid: Sílex, 2013, pp. 157-176. 
entonces. En corto espacio de tiempo, estas instituciones educativas se manifestaron como notablemente útiles a la institución castrense y a la Monarquía ${ }^{33}$, así como sus oficiales, leales servidores del rey. Tras la guerra de Sucesión se fundaron los primeros colegios y academias militares ${ }^{34} \mathrm{y}$ las promociones formadas en ellos incrementaron el prestigio de aquellas instituciones docentes y de la milicia borbónica, con individualidades destacadas que dinamizaron no solo la profesión militar, sino la Ilustración española ${ }^{35}$ en ámbitos como el científico, técnico o cultural. Los oficiales ilustrados fueron vehículos de transmisión de la nueva ciencia y técnica en nuestro país, secundando a la Corona en el proceso de modernización de España en el XviII. Desde hace muchos años y desde el entorno investigador de la historia de la ciencia $^{36}$ se ha puesto de manifiesto su protagonismo en el desarrollo científico, cultural y tecnológico. Las actividades científicas y militares en el XVIII español compartieron lugares comunes, objetivos y proyectos, y en las últimas décadas la historiografía ha puesto de manifiesto que, en un buen número de casos el científico español en la Ilustración, vestía un uniforme ${ }^{37}$.

\subsection{Formación de los ingenieros militares. Academia de Barcelona}

A principios del XVIII, por iniciativa de Felipe V se abrió la Academia de Matemáticas de Barcelona, fundación estrechamente vinculada al teatro catalán de la guerra y a las necesidades perentorias de defensa como consecuencia del conflicto sucesorio. El referente y modelo para la apertura de la Academia de Matemáticas de Barcelona fue sin duda la Academia de Bruselas, llegándose a implicar el propio Medrano como asesor, para formar oficiales de todas las armas. Es más, el elegido por Felipe $\mathrm{V}$ para diseñar la enseñanza académica de los ingenieros militares fue un antiguo alumno del centro flamenco y prestigioso ingeniero militar al servicio

33. HERRERO FERNÁNDEZ-QUESADA, María Dolores. Cienciay milicia en el siglo XVIII. Tomás de Morla, artillero ilustrado. Segovia: PAS, 1992 y Diccionario biográfico de la Real Academia de la Historia. Voz Tomás Bruno de Morla Pacheco. https://dbe.rah.es/biografias/13338/tomas-bruno-de-morla-pacheco.

34. Estos centros estaban destinados a instruir a los oficiales de la Armada en San Fernando y a los miembros de los Cuerpos Facultativos, Ingenieros en Barcelona; Artillería en Cádiz y Barcelona, y finalmente ya en el reinado de Carlos III, como único centro docente para la formación de futuros oficiales de Artillería, el Real Colegio de Segovia.

35. Herrero Fernández-Quesada, María Dolores. "Consideraciones en torno a la enseñanza artillera en el siglo XVIII. La proyección científico-técnica de los artilleros». En GimÉNEZ, Enrique y BaLAGUER, Emilio (eds.). Actas del Congreso Ejército, Ciencia y Sociedad en la España del Antiguo Régimen. Alicante: Instituto de Cultura Juan Gil-Albert, 1995, pp. 407-433.

36. Sellés, Manuel; Peset, José Luis y LAfuente, Antonio. Carlos III y la ciencia de la Ilustración. Madrid: Alianza Editorial, 1988; PESET, José Luis y LAFuEnTE, Antonio. "Las Academias militares y la inversión en ciencia en la España Ilustrada». Dynamis, 1982, 2; LóPEZ PIÑERO, José María. La introducción de la ciencia moderna en España. Barcelona: Ariel, 1969.

37. Herrero Fernández-Quesada, María Dolores. Ciencia y milicia en el siglo XVIII. Tomás de Morla, artillero ilustrado. Segovia: PAS, 1992. 
M. ${ }^{a}$ DOLORES HERRERO FERNÁNDEZ-QUESADA

SISTEMAS DE CAPTACIÓN E INNOVACIÓN EN LA FORMACIÓN DEL MILITAR BORBÓNICO...

de la Monarquía, Próspero Verboom, quien ya nombrado ingeniero general asumió primero el proceso de creación del Cuerpo de Ingenieros y, después, reguló la formación de sus oficiales con la fundación de la Academia de Barcelona que, de 1720 a 1738, fue dirigida por Mateo Calabro y desde 1739 por Pedro de Lucuze, hasta 1756. Los planteamientos de la nueva política científica borbónica y de la nueva política militar convergieron en este prestigioso centro que este año conmemora su 300 aniversario.

Con respecto a Verboom cabe señalar que su padre fue su mentor profesional, pues pertenecía a una saga de ingenieros militares al servicio del rey ${ }^{38}$, resultando además definitivo su ingreso y formación con Sebastián Fernández de Medrano en la Real y Militar Academia del Ejército de los Países Bajos. Junto a esto hay que sumar la experiencia profesional acumulada en los años que sirvió en los ejércitos de Flandes de Carlos II, alineado con los aliados frente a Luis XIV, sobre organización, tácticas, infraestructuras y logística de los contingentes militares en campaña; así como su trayectoria como ingeniero mayor desde finales del XVII y sobre todo junto a Vauban en los primeros años de la guerra de Sucesión en Flandes, le valieron situarse, a ojos de la Corona, como primera opción para desempeñar el empleo de ingeniero general ${ }^{39}$. La idoneidad de Verboom está fuera de dudas como demuestra el repaso a su cursus honorum y la documentación militar lo refrenda ${ }^{40}$, así como sus proyectos innovadores en España ya como ingeniero general: la publicación de la Ordenanza de 1718 que fijó los criterios fundacionales del Cuerpo o el control defensivo del territorio y la gestión y actualización de las defensas peninsulares. Y, junto a ello, la fundación del colegio para los ingenieros militares. Verboom fue su autor intelectual pero también su brazo ejecutor. En el proyecto del colegio de Barcelona y de institucionalización del Cuerpo de Ingenieros, ayudó indirectamente la pérdida de los Países Bajos, que propició la emigración de ingenieros militares más aún ante los retos defensivos en la Península, que participaron activa y eficazmente en todo el proceso. El estudio de este grupo de militares nos ha permitido concluir que existían estrategias profesionales y familiares generalizadas cuyos efectos perduraron a lo largo de la centuria. Sin embargo, hemos advertido que no se trató de un fenómeno de nuevo cuño iniciado en 1709, sino que las fuentes nos proporcionan numerosos precedentes del siglo anterior ${ }^{41}$. Flandes, permanente teatro

38. De hecho, dos hijos suyos ingresaron después en la Academia de Barcelona.

39. Por todo ello, la hoja de servicios de Verboom recogía un cursus honorum inmejorable que reunía los requisitos necesarios para hacerse cargo de ambos empleos militares y la fundación del Real Cuerpo de Ingenieros de España. Véase AGS, Guerra Moderna, legajo 3799, Resumen de los servicios del difunto Don Jorge Próspero de Verbóon y empleos que ocupó, asi en la infantería como caballería, en los ejércitos de Flandes, España y otros parajes, Madrid, 1744; AGS, Guerra Moderna, Indiferente de Ingenieros, legajo 3799; AGMS, Sección 1, Célebres, Caja 139.

40. AGS, Guerra Moderna, legajo 3799, Resumen de los servicios del difunto Don Jorge Próspero de Verbóon... En total, ejerció su carrera militar 66 años, 11 meses y 19 días de sus 79 años de vida.

41. AGS, Guerra Moderna, legajo 1973. 
de guerra, era junto a Italia el principal centro de formación de ingenieros de la Monarquía Hispánica.

Con estos mimbres, se abrió la Academia de Matemáticas de Barcelona, que sufrió en sus primeros años el devenir de las campañas sucesorias. Sobre los planteamientos de la Academia de Bruselas y con la asesoría de Medrano, se diseñó el modelo de centro, su ideario docente, metodología de la enseñanza y materias de estudios científico-técnico-militares necesarias para la formación de los ingenieros militares españoles. El centro barcelonés arrancó su andadura sin interrupciones ya desde 1720, y hasta 1738 fue dirigido por Mateo Calabro y desde 1739 por Pedro de Lucuze hasta 1756, con quien se cerró este modelo académico ya consolidado. Para su estudio hay que seguir referenciando la obra ya clásica de Capel, estudio global de esta institución, sus planteamientos fundacionales, planes de estudio y metodología docente innovadoras en el ámbito de la educación militar, acompañados de un solvente claustro de profesores de importante formación teórica, pero también práctica, de los que fue paradigma el propio director Verboom $^{42}$. Poco hay que añadir al respecto. Barcelona fue el primer colegio militar abierto para la formación de los oficiales de aquel Cuerpo Facultativo, estructura académica sobre la que se levantarán las siguientes escuelas o colegios militares borbónicos, marcando el modelo. El mejor calibrador científico de la Academia de Barcelona será la obra que los ingenieros militares allí formados dejaron formando parte del patrimonio peninsular y ultramarino.

\subsection{Dispersión en la formación de los artilleros}

Desde el reinado de Felipe $\mathrm{V}$ en adelante, el proceso de adopción de un sistema de formación para los artilleros fue largo y -a diferencia de los ingenieros- con el hándicap de no haber sido creado aún el Cuerpo de Artillería en la orgánica de los ejércitos permanentes. Las nuevas coordenadas para la enseñanza de la artillería se fijaron en el Reglamento y Ordenanza para la más acertada y puntual dirección de mi artillería $(1710)^{43}$, que marca un antes y un después, pues por primera vez se reconoce en ella la separación de los ingenieros militares de los artilleros - antes trufados en los contingentes militares de la Monarquía- tras la creación del Cuerpo de Ingenieros bajo la dirección de Próspero Verboom.

42. Galland-Seguela, Martine. Le ingenieurs militaires espagnols de 1710 à 1803 . Étude prosopographique et sociale d'un corps d'élite. Tesis doctoral. École des Hautes Études en Sciences Sociales. Director Bernard Vincent, Paris, 2003, y «Las condiciones materiales de la vida privada de los ingenieros militares en España durante el siglo XVIII». Scripta Nova: Revista Electrónica de Geografía y Ciencias Sociales, 2004, 8, pp. 157-180; Molas Ribalta, Pere y SEgovia Barrientos, Francisco (coords.). La Academia de Matemáticas de Barcelona. El legado de los Ingenieros Militares 1720-1803. Barcelona: Museu Marítim de Barcelona, 2004.

43. Reglamento y Ordenanza para la más acertada y puntual dirección de mi artillería, 1710. En adelante los entrecomillados pertenecen a este texto. 
Pendiente la institucionalización del Cuerpo de Artillería en las nuevas estructuras militares, desde el punto de vista de la educación artillera, el reinado de Felipe $\mathrm{V}$ se define en principio por la dispersión de centros diversos en los que quienes querían instruirse en la ciencia artillera se formaban. Diversidad de centros y dispersión también geográfica, con escuelas en diferentes puntos de la Península. Un segundo factor marca la diferencia en el ámbito de la formación para la artillería, que se distingue por la necesidad de apertura de centros para instrucción de tropa, además de para oficiales. De ahí que una lectura en diagonal de la Ordenanza puede llevar a la confusión cuando se refiere a la creación de escuelas y, especialmente, a quienes serían sus destinatarios. Así, al hablar de instrucción artillera, hay que hacer una precisión que históricamente y de forma consuetudinaria era asumida por todos, pero que, con el Reglamento de 1710, se pone negro sobre blanco, y que requiere una precisión conceptual clarificadora. Cuando se hace referencia a la apertura de centros de formación no necesariamente eran para oficiales, sino que los artilleros, los servidores de los cañones, también necesitaban pasar por escuelas para adquirir el conocimiento y destreza en la práctica artillera y el tiro. De tal forma que en esta Ordenanza de 1710 encontramos el origen de la apertura reglada de centros para la instrucción para la tropa, los artilleros que en el XVIII debían servir los materiales con una formación que, secularmente, se había convenido en entender como más que compleja y que requería un periodo previo de instrucción y praxis artillera. La tropa de artillería nunca se improvisó. De acuerdo con ello, en este Reglamento leemos "ordeno y mando haya cuatro Escuelas de Artillería y Bombas; una en Aragón, otra en Extremadura, otra en Andalucía y la otra en Galicia, en que se adiestren, experimenten y ejerciten los Artilleros y Bombarderos, a fin de crearse prácticos y hábiles para mi Real Servicio...», primando la instrucción en la praxis artillera secularmente. Paralelamente y en la misma Ordenanza, por el artículo 16 se reguló que hubiera "otras tres escuelas y academias militares; una en Aragón, otra en Extremadura y la tercera en Andalucía donde se enseñe las matemáticas y particularmente la fortificación y todo lo que toca a la defensa y ataque de las plazas; la Geografía, campamento de las tropas, formación y movimiento de batallones y otros ejercicios militares; instruyendo también a los artilleros, bombarderos y demás soldados de artillería.... ${ }^{44}$, texto del que se desprende con nitidez quiénes estudiarán en esos centros, pues los contenidos científico-técnicos y militares iban dirigidos a los futuros oficiales, por el nivel de los contenidos descritos, necesarios para la oficialidad artillera por la complejidad de la artillería como sistema de armas. Asistimos aquí al principio del fin de un largo periodo histórico marcado por el empirismo. Cabría añadir que,

44. Con un carácter más particular y local, por iniciativa del comandante de Artillería de Navarra, en 1720 se creó una Academia de Artillería en su domicilio familiar de Pamplona con el fin de que sus subordinados aprovecharan los tiempos muertos en beneficio de su formación, asistiendo también de otras unidades e incluso paisanos. 
M. ${ }^{a}$ DOLORES HERRERO FERNÁNDEZ-QUESADA

SISTEMAS DE CAPTACIÓN E INNOVACIÓN EN LA FORMACIÓN DEL MILITAR BORBÓNICO...

siguiendo la misma política educativa, en 1739 se abrieron las academias militares de Barcelona y Orán para formar oficiales de artillería ${ }^{45}$; el principio del fin de un largo periodo histórico marcado por el empirismo que dio paso en el XVIII a la ya mencionada alianza entre ciencia y artillería, que nos lleva ya en plena Ilustración a la consideración de la ciencia artillera. No obstante, las actividades docentes militares en la Península se paralizaron temporalmente como consecuencia del sitio de Gibraltar en 1727, por lo que hasta 1730 no podemos hablar de una normalización y continuidad de las actividades académico-formativas.

Ya desde el reinado de Felipe $\mathrm{V}$ podemos establecer un balance comparado entre los dos sistemas de formación de oficiales que coexistieron y que nos lleva a aportaciones claras en este sentido. Si estableciéramos un virtual ejercicio de estudio comparado entre el sistema de formación de oficiales en las unidades como Cadetes de Regimiento y el de los colegios militares, en el largo reinado de Felipe $\mathrm{V}$ se imponen las ventajas y resultados de los colegios militares. Avanzando en las décadas del XVIII y, desde el principio, se pone de manifiesto la superioridad de la instrucción de los militares en centros docentes: el internado durante años garantizaba sin duda una formación de élite por la disciplina académica y clima de estudio; por una formación muy homogénea para todos los oficiales de los Cuerpos Facultativos (no atribuible al Cadete de Regimiento, cada uno tutorizado según el diferente criterio y vocación docente del maestro de Cadetes); y porque la convivencia continuada fomentaba los intangibles que cohesionaban la unidad de Cuerpo, la transmisión de valores y la inoculación del ideario ilustrado de la Monarquía. Empatía constatada, e implicación en la consecución de los objetivos de esa política. También porque la convivencia en régimen de internado académico propiciaba estrechar lazos de lo que pronto se llamó familia militar, lazos entre oficiales de promoción que se mantienen a lo largo de sus trayectorias profesionales y vitales por medio de las bodas con familiares de compañeros, atenciones, epistolarios, favores, recomendaciones... Pero si un factor resulta ser determinante para la inclinación de la balanza hacia el sistema de formación de los colegios militares, fueron los resultados incontestables encontrados a su favor, al seguir las trayectorias de los oficiales allí promovidos con un nivel sin parangón, pues, a lo largo del siglo XVIII, el perfil del militar ilustrado aumentaba su cotización al alza, especialmente en el caso de los ingenieros y los artilleros. Los primeros tras su instrucción académica y militar en sus respectivos colegios presentan además un perfil científico-técnico muy notable no solo por su formación de élite, sino también por sus competencias y sus respectivas trayectorias profesionales vinculadas para los ingenieros a las grandes obras de la arquitectura e ingeniería militar, e incluso

45. De las que se sabe poco más de lo ya publicado por los clásicos como Vigón SuERO-Díaz, Jorge. Historia de la Artillería Española. Madrid: CSIC, 1947. 3 tomos, y SALAS, Ramón. Memorial histórico de la Artillería Española. Madrid: Imprenta que fue de García, 1831. 
M. ${ }^{a}$ DOLORES HERRERO FERNÁNDEZ-QUESADA

SISTEMAS DE CAPTACIÓN E INNOVACIÓN EN LA FORMACIÓN DEL MILITAR BORBÓNICO...

del urbanismo ${ }^{46}$; mientras que para los artilleros -además de la complejidad de dominar su sistema de armas- vinculadas al proceso de estatalización y despegue de la industria bélica española, como directores de las fábricas. Con ingenieros y artillería se pusieron las bases de la enseñanza militar ilustrada al fundarse sus respectivos colegios militares. En aquellos centros se iban a formar promociones de oficiales cuya primera seña de identidad iba a ser su educación, sin duda de élite, de fuerte base científico-técnica ${ }^{47}$, que es la esencia del alto perfil de los militares de los Cuerpos Facultativos en el XVIII. De ahí la intervención en su estudio e investigación de los historiadores de la ciencia y la técnica ilustradas.

En síntesis, cabe señalar en un primer análisis que el sistema/modelo educativo no fue homogéneo, sino claramente desigual, con resultados también desiguales, y presentando diferentes perfiles profesionales muy distantes entre sí, en ocasiones. Y esa desigualdad abocó al fracaso al modelo educativo militar que entró en crisis a finales de siglo, evidenciando sus fallas y fisuras para una mayoría de oficiales, a tenor de los resultados. No fue así para una minoría, formada en colegios, ingenieros, artilleros y marinos. Las ventajas estaban claras, el sistema necesario para la formación operativa de oficiales era la institucionalización definitiva para todos, y hubo varios intentos a lo largo del XVIII para abrir colegios específicos para Infantería y Caballería, aunque presentan una corta vida como la escuela de Ávila ${ }^{48}$.

\section{CON FERNANDO VI, CONTINUIDADES, INNOVACIÓN Y PROYECTOS EFIMEROS}

En una breve evocación para tan corto reinado, bien puede decirse que el legado academicista para la formación de los ingenieros militares recibido del reinado de Felipe $\mathrm{V}$ fue el único que cerró modelo y, con el advenimiento de Fernando VI, una etapa de consolidación, siendo la continuidad la nota distintiva de la educación de los ingenieros militares y el devenir de su academia. No podemos aseverar lo mismo de la formación de los oficiales de artillería que vivió una etapa experimental en este reinado y antes de la definitiva institucionalización en un solo centro. El Colegio de Ingenieros de Barcelona tenía una trayectoria

46. Herrero FernándeZ-Quesada, María Dolores. "La ciencia y técnica militar». En VV. AA. Aproximación a la historia militar de España. Madrid, 2006, vol. 3.

47. Capel SÁEZ, Horacio; SÁnchez, Joan Eugeni y Moncada, Omar. De Palas a Minerva La formación científica y la estructura institucional de los ingenieros militares en el siglo XVIII. Madrid: Serbal, 1988. Herrero Fernández-Quesada, María Dolores. «El Real Colegio de Artillería. De la fundación a la consolidación de un modelo de centro docente militar y científico-técnico". Revista Historia Militar. 250 aniversario del Real Colegio de Artillería. Instituto de Historia y Cultura Militar, 2014, 58, 1, pp. 73-133.

48. RECIO MORALES, Óscar. "Innovación militar en la España del siglo XVIII: la producción científica de la Real Escuela Militar de Ávila (1774)». En Herrero FERnÁNDEZ-QuesADA, María Dolores (coord.). Entre Marte y Minerva. Los Reales Ejércitos Borbónicos, del reformismo al mito. Cuadernos de Historia Moderna, 2016, 41, 2, pp. 425-442. 
fundacional y que permite constatar su consolidación como centro docente militar y su prestigio reconocido, visibilizado materialmente -en la Península y Ultramaren la obra de los ingenieros militares que de allí fueron promovidos, así como en sus trayectorias profesionales. Su orgánica y su metodología docente eran el anclaje sobre el que se iba articulando la innovación en la educación para la guerra, a través de la ampliación de los planes y materias de estudio y la reorientación de sus contenidos y edición de textos para la enseñanza al compás del progreso científico-técnico y militar del siglo ilustrado ${ }^{49}$. En las clases magistrales, los alumnos tomaban apuntes manuscritos que, después, presentaban a evaluación y de los que afortunadamente se conservan ejemplares que acreditan el alto nivel de la enseñanza, como un tratado manuscrito fechado en 1757 con los contenidos del tratado quinto de artillería que se impartía a los futuros ingenieros en Barcelona ${ }^{50}$. Esta metodología docente se mantuvo en Barcelona largo tiempo hasta que en la segunda mitad del XVIII empezaron a imprimirse sus manuales, lo mismo que después sucedería en el Colegio de Segovia. Entre esos apuntes manuscritos de la Academia de Barcelona, cobran especial importancia los ejemplares de Cadete que han llegado hasta nosotros del curso de fortificación que impartía Lucuze y que años después se dio a la imprenta como manual de culto ${ }^{51}$, así como los tratados de matemáticas ${ }^{52}$. Para entonces la Academia de Barcelona, junto a la de Guardiamarinas de Cádiz, eran una referencia obligada, un espejo al que mirar cuando se trabajaba en la apertura de nuevos colegios militares.

49. Archivo General Militar de Madrid, Ingenieros, G-9. a, 9 y 10. RABANAL Yus, Aurora. «El tratado de arquitectura enseñado en la Real y Militar Academia de Matemáticas de Barcelona». Anuario del Departamento de Historia y Teoría del Arte, 1990, 2, pp. 179-185.

50. BCM (IHCM), Ms-436. Agradezco su ayuda para la localización al director de la Biblioteca Central Militar, Fernando Torra.

51. Lucuze, Pedro. Principios de Fortificación, que contienen las definiciones de los términos principales de las obras de Plaza, y de Campaña, con una idea de la conducta regularmente observada en el Ataque y Defensa de las Fortalezas. Barcelona: Thomas Piferrer, 1772. Y en BCM, Lucuce, Pedro de (1692-1779); Curso inédito de matemáticas, fortificación, artillería, cosmografía y arquitectura que sirvió de texto en las academias militares / [Pedro de Lucuze] - [1759-1761]. Incluye: «Noticia biográfica de D. Antonio Remón y Zarco Torralbo y Orbaneja” y carta de donación a la Biblioteca del Cuerpo de Ingenieros escritas y dedicadas por su hijo Antonio Remon Zarco del Valle el 19 de noviembre de 1843. En la p. [1] de la "Noticia biografica" figura el autor de la obra "Curso Matematico". En el lomo de la caja: «Escrivio este egemplar por los años 1760 D. Antonio Remon Zarco del Valle». Contiene: Tratado I. Curso matemático para la instrucción de los militares Introducción - Tratado II. De la geometría elemental - Tratado III. De la geometría práctica - Tratado IV. De la fortificación - Tratado V. De la artillería - Tratado VI. De la cosmografía - Tratado VII. De la Statica; Curso de mathemática para uso de los Ingenieros. Manuscrito, 9 tomos en $8 .^{\circ}$.

52. Curso de mathemática para uso de los Ingenieros. Manuscrito, 9 tomos en $8 .^{\circ}$. Se conservan ejemplares manuscritos de alumnos en la BCM (Instituto de Historia y Cultura Militar) con diferente cronología; y también se registraron ejemplares manuscritos de fortificación en el inventario de la Biblioteca de la Academia de Artillería de Segovia. 
M. ${ }^{a}$ DOLORES HERRERO FERNÁNDEZ-QUESADA

SISTEMAS DE CAPTACIÓN E INNOVACIÓN EN LA FORMACIÓN DEL MILITAR BORBÓNICO...

El segundo Cuerpo Facultativo, aún por organizar y reglamentar, de los Reales Ejércitos Borbónicos, el de Artillería, por su vis científico-técnica e industrial no pudo ser reformado y abordada su orgánica definitiva con Felipe V, cuyos ministros más se preocuparon por el reto de la actualización en la fabricación de los cañones y piezas de artillería, sus establecimientos fabriles, que en fijar el nuevo sistema de la artillería española acorde con las tendencias europeas, especialmente francesas, y reglamentarlo de forma homogénea en todas las fundiciones españolas imponiendo criterios únicos y obligatorios a los asentistas que obtuvieron los contratos y que ya nunca más podrían gestionar el asiento y entregar los materiales a su albur y sin control. Esta actividad industrial de la artillería, clave en la formación de unos ejércitos permanentes, se priorizó sobre la orgánica del Cuerpo que, aún a la llegada de Carlos III, estaba sin crear, sin reglamento ni ordenanza constitucional, tan solo con un Regimiento de Artillería. Por lo que se refiere a la educación militar de los artilleros, tampoco se había tocado la tecla definitiva y, decidiéndose por la formación en colegios militares por su enorme carga científica y complejidad de la praxis artillera, desde el Gobierno y con Ensenada se articuló una bicefalia colegial al determinar que habría dos centros de instrucción para los artilleros en dos ciudades emblemáticas y no seleccionadas por azar: Barcelona y Cádiz. Los años de rodaje de estas dos academias, los alumnos allí formados, la determinación de una metodología docente y la incardinación en los planes de estudios de la potente teórica artillera con la necesaria praxis pusieron las bases de la solución definitiva sustanciada en un único colegio artillero para la formación de sus oficiales a partir de 1764. Desde el Gobierno, los ministros trabajaron en la búsqueda del cierre del sistema de formación de los artilleros, experimentando con el modelo. Así, en una somera descripción de esta experiencia docente bipartita, repartida entre Cádiz y Barcelona, cabe recordar que se desenvuelve en un marco histórico y político muy determinado y determinante. En el reinado de Fernando VI, marcado por la neutralidad y la "paz armada", se asiste al desarrollo de una interesante política reformista generalizada, y en la enseñanza de la artillería se produjo un notable avance en la unificación de criterios con la apertura en 1751 de las escuelas de Cádiz y Barcelona para los oficiales de artillería, representando además la independencia docente con respecto a los ingenieros militares. Sin embargo, estos dos colegios militares de la primera mitad del XVIII tenían en común su organización; la metodología docente; los planes de estudios de fuerte carga científico-técnica para lograr la excelencia en la práctica artillera; y, curiosamente, la convocatoria de «certámenes públicos» o exámenes públicos en los que los alumnos mostraban sus progresos y conocimientos científico-militares. La motivación de los jóvenes aspirantes a militares se cubría con "premios» a los destacados que solían ser «estuches matemáticos», libros o incluso medallas conmemorativas ${ }^{53}$.

53. AGS, Guerra Moderna, legajo 11. «Relación actual de la Real Escuela de Artillería de Cádiz, del curso que el Comisario Ordinario D. Gabriel Martínez ha compuesto para su establecimiento con 
Es interesante reparar en este proceso de adopción del sistema de formación artillera, que en el reinado de Fernando VI por inspiración de Academia de Artillería fundada por su hermano Carlos en Nápoles en 1746, y también por las inquietudes de alguno de sus competentes ministros en el ramo militar, se acomete la creación de estos centros para la enseñanza de artillería. De esta forma en noviembre de 1751 se prescribió por una Real Ordenanza «sobre lo que se ha de observar en las Escuelas de Matemáticas, que con el título de Artillería, ha mandado S.M. erigir en las plazas de Barcelona y Cádiz bajo la Dirección del Cuerpo General de ella ${ }^{54}$. Dos ciudades de larga historia defensiva y tradición artillera (eran entonces las sedes de las planas mayores de los dos batallones), pero también docente, que habían sido recurrentemente sedes de colegios, escuelas o academias de artillería y matemáticas. Pero su importancia a corto y medio plazo fue decisiva, pues estas dos casi desconocidas escuelas son el precedente más claro e inmediato de la fundación en el siguiente reinado de un solo centro para la promoción de la oficialidad artillera, el Real Colegio de Segovia. Ciertamente su trayectoria docente resultó ser muy valiosa para sentar las bases, y la documentación consultada de estos dos centros acredita el alto nivel científico de sus estudios (estructurados en cuatro cursos anuales) que ponen de manifiesto las materias de sus planes de estudio y los llamados "Escrutinios» a los que se sometía a los alumnos, que se conservan en Simancas, porque así llamaban entonces a los exámenes o pruebas docentes. Gracias a esto, constatamos el nivel y composición de las enseñanzas y el amplio espectro de materias que ya integraban sus planes de estudios. Como aportación ilustrativa en este sentido, utilizaremos únicamente un «Escrutinio» celebrado en 1752 que explicita las materias y disciplinas que debían dominar los artilleros dieciochescos y que figuran en el encabezamiento del documento que habla por sí mismo:

Escrutinio mathemático que se ha de celebrar en la Real Escuela de Cádiz del cargo de el Cuerpo General de Artillería. Los académicos de la segunda clase aspiran a demostrar a la suerte... las Proposiciones Theoremas y Problemas mas principales de las Arithmeticas Numérica y Literal; Algebra hasta el segundo grado: Questones de Progressiones, y Aligaciones resueltas por Análisis. La Geometría especulativa, y Práctica; allí en lo que comprehenden los doce libros de Euclides, y Selectas de Archimedes; como en operaciones en la campaña con varios instrumentos: Las Secciones Cónicas, Parabola, Elipse, y Yperbola, demostradas Analíticamente: Concluyendo con los Calculos Potencial, Radical, Diferencial, y Integral. El número de Proposiciones pasará de trescientas, repartidas en seis barajas; a fin de que indistintamente comprehenda la suerte todas las expressadas Materias... ${ }^{55}$.

las máximas, que por su dirección se han practicado, y practican con el consentimiento de D. Juan Manuel de Porres, Teniente Provincial e Ynspector de dicha Escuela».

54. AGS, Guerra Moderna, legajo 572.

55. AGS, Guerra Moderna, legajo 572. 
Se constata así una vez más, por este y otros medios documentales, la fundamentación científica y, especialmente, matemática de la práctica artillera, ante los exámenes a que eran sometidos los alumnos a mediados del siglo XVIII. Sin duda, las bases de la institucionalización de la enseñanza artillera se pusieron en las dos escuelas de Barcelona y Cádiz y quedó para el reinado siguiente cerrar el modelo docente consolidado con la fundación del Real Colegio de Artillería de Segovia desde 1764. Cabe señalar así que esta documentación pone de manifiesto una aportación destacable, el entronque estructural con estas dos academias periféricas del ideario docente fundacional del futuro centro docente segoviano. El estudio de estos dos colegios artilleros y su trayectoria experimental fueron los cimientos sobre los que se levantó un único colegio de artillería, pues uno de los pilares estructurales de la innovación militar que representa el sistema académico del centro segoviano también se conjuga en ambos: la necesidad de articular una potente formación teórica para los alumnos, combinada con la práctica. En este sentido hay que reparar en una precisión determinante: iban oficiales o suboficiales a completar estudios y ampliar formación, pero también entraban nuevos aspirantes. Para la formación práctica, en este sentido, se prescribió igualmente que se restablecieran las Escuelas de ejercicios en las plazas de Barcelona y Cádiz, eligiéndose en la Secretaría del Despacho Universal de la Guerra como directores a dos comisarios provinciales. Del tono científico de la escuela gaditana nos habla, por un lado, la talla de los oficiales formados en Cádiz, ilustres artilleros como Vicente Gutiérrez de los Ríos, quien tras su etapa formativa allí, fue promovido a oficial ${ }^{56}$. Y, por otro, la constatación documental de que se invirtieron esfuerzos en la formación de una excepcional biblioteca de materias científicas y militares, con volúmenes encargados y comprados por Jorge Juan que se unieron al legado de fondos de la Biblioteca de la extinta Real Sociedad Matemática de Madrid ${ }^{57}$.

Asimismo en aquel reinado se dio un importante avance en la instrucción de la tropa artillera. Los fundamentos y procedimientos de la praxis artillera fueron abordados - por iniciativa de Araciel, coronel del Regimiento de Artillería- mediante la edición, en enero de 1750, de la Ordenanza de exercicio para el cañon, mortero y cabria ${ }^{58}$, texto de cabecera de la artillería española en la época. En artillería, la formación de la tropa era deudora de las dificultades que presentaba este sistema de armas. Retomando la tradición academicista artillera, ya mencionada, y para formar a la tropa de artillería, en esta práctica ordenanza el rey entendía que convenía

56. AGS, Guerra Moderna, legajo 2504, un ejemplar de su Hoja de Servicios. AGMS, sección primera, legajo G-4386. Expediente personal de Ríos.

57. AGS, Guerra Moderna, legajo 560.

58. AGS, Guerra Moderna, legajo 571. 
M. ${ }^{a}$ DOLORES HERRERO FERNÁNDEZ-QUESADA

SISTEMAS DE CAPTACIÓN E INNOVACIÓN EN LA FORMACIÓN DEL MILITAR BORBÓNICO...

a mi servicio se instruyan los Artilleros y Bombarderos con escuela práctica del exercicio del Cañón, Mortero y Pedrero con fuego, y sin él, y en el de la cabria; y que en todas las plazas se execute uniformemente con la posible reducción de voces, y explicación de los principales puntos omitidos hasta aora: He resuelto, que para la más fácil comprehensión de los expressados exercicios, se dirijían en la forma, que comprehenden los capítulos siguientes...

Para finalizar, apenas un recuerdo testimonial a una ilusión efímera, aunque premonitoria, un paso más allá en el proceso de innovación docente militar. Por iniciativa del conde de Aranda se abrió en Madrid una innovadora institución, la Real Sociedad Militar Matemática de Madrid, de corta vida, pues desapareció cuando Aranda perdió el poder. Sin duda en su planteamiento fue una academia destinada a completar la formación científico-técnico-militar de los oficiales de artillería e ingenieros, incorporando la investigación aplicada a la formación militar ${ }^{59}$. Sus miembros, todos de los Cuerpos Facultativos, con la base de una excepcional biblioteca debían crear ex novo apoyos a la enseñanza para la guerra, un repositorio de herramientas para el perfeccionamiento de la formación de los oficiales, desde manuales a maquetas o cartografía ${ }^{60}$.

\section{Carlos III: inNOVACión y modelo aCADÉMiCO, El Colegio DE ARTillería}

En este reinado se mantiene la academia de ingenieros de Barcelona en la misma línea de ascenso exponencial en el nivel de sus enseñanzas, pilotada por el experimentado Pedro de Lucuze, que por fin dio a imprenta como texto del centro sus clásicos Principios de fortificación (1772), después libro de texto en otras academias para el estudio de la arquitectura militar. En este epígrafe nos detendremos más en el paradigma del modelo de la enseñanza militar ilustrada con la fundación de un colegio que consolidó y presenta una inédita continuidad en el tiempo. En trabajos anteriores sobre el Real Colegio de Artillería ya mostramos el centro como paradigma de la innovación de la enseñanza militar científico-técnica ${ }^{61}$, lo que supuso el cierre del modelo ${ }^{62}$. El programa organizativo de reformas militares borbónicas afectó de lleno en el reinado de Carlos III a la

59. Marzal Martínez, Amparo. «Un ejemplo de renovación científica en la Ilustración. La Real Sociedad Militar Matemática de Madrid». Temas de Historia Militar, Actas del Congreso de Historia Militar de Zaragoza, 1982.

60. Puell de la Villa, Fernando. Origen, vida y reclutamiento del infante español. Tesis doctoral dirigida por Enrique Hernández Sierra y Sonia Alda Mejías. UNED, 2016; CAPEL SÁEZ, Horacio; SÁNCHEZ, Joan Eugeni y MONCADA, Omar. De Palas a Minerva: la formación científica y la estructura institucional de los ingenieros militares en el siglo XVIII. Madrid: CSIC, 1988.

61. HERRERO FERNÁNDEZ-QueSADA, María Dolores. "La innovación militar en el siglo XVIII. Felice Gazzola y el Real Colegio de Artillería de Segovia». Rivista Storica Italiana, 2015, pp. 211-247.

62. Imízcoz BeunZA, José María y CHAPARRo, Álvaro (eds.). Educación, redes y producción de élites en el siglo XVIII. Madrid: Sílex, 2013 
artillería. Es un periodo en la historia del arma que ya conocemos e identificamos con las llamadas "reformas artilleras del Conde de Gazola». Cuando Carlos III llega a la Península procedente de Nápoles para asumir la Corona, sobre la base de la organización de los ejércitos permanentes y la Armada que le legaron su padre y hermano respectivamente, el nuevo rey va a prestar especial atención, en el marco de su política militar, a las aún pendientes reformas artilleras que eran muchas y ya perentorias. Su mentor y leal consejero Tanucci le propuso que incorporara a su equipo en España y trajera desde Nápoles a uno de sus más estrechos colaboradores, el conde Felix Gazola, militar de sólida formación científica, humanística y matemática que presentaba un perfil inequívocamente ilustrado. Abundando en su idoneidad para materializar lo que, sin duda, fue un proyecto de Estado, cabe recordar que Gazola había sido con el rey Carlos VI de Nápoles comandante general de la Artillería napolitana, además de leal consejero y asesor del monar$\mathrm{ca}^{63}$. Históricamente ha sido considerado como el fundador del Real Cuerpo de Artillería español y del Colegio de Segovia, todo ello en el marco de un reinado reformista tanto que, historiográficamente, se ha atribuido a Carlos III el título de monarca ilustrado y reformador por excelencia. En esta tarea, la acertada elección de los equipos de ministros y colaboradores fue clave y, en la primera etapa de su reinado, lo que en otro lugar hemos definido como el «equipo italiano" del rey puso en marcha los criterios sobre los que iba a pivotar la política militar en términos generales, y las reformas artilleras en particular. Habiendo institucionalizado Felipe V el Cuerpo de Ingenieros Militares, faltaba el segundo Cuerpo Facultativo, la artillería, así desde 1762 -según el proyecto elaborado por Gazola desde que llegó a España- ya estaba configurada la nueva estructuración orgánica del naciente Cuerpo de Artillería. De hecho, en enero de 1762 fue aprobada por S. M. y dada a la imprenta la Ordenanza en la que se condensaron las trascendentales reformas artilleras, el Reglamento del nuevo pie en que S.M. manda que se establezca el Real Cuerpo de Artillería, dividido en 27 títulos de contenido decisivo para el futuro de la artillería en España. Con su entrada en vigor, se dio carta de naturaleza a la definitiva separación de los Cuerpos de Ingenieros y Artillería, secularmente colindantes en el universo militar y que con el conde de Aranda fueron fugazmente fusionados. Desde 1762 el conde de Gazola fue el único director general de Artillería, consolidando el cargo y sus funciones con su gestión hasta su fallecimiento en $1780^{64}$. En suma, las aportaciones claves de este Reglamento,

63. Encontramos que el 2 de agosto de 1761 se expidió su despacho como teniente general de los Reales Ejércitos, encomendándosele después la Inspección General de Artillería dependiente de la Secretaría del Despacho de la Guerra, para abordar la definitiva organización de la artillería española. AGS, Guerra Moderna, legajo 3. Expediente personal del Conde de Gazola.

64. HERRERO FERNÁNDEZ-QuESADA, María Dolores. "La innovación militar en el siglo XVIII. Felice Gazzola y el Real Colegio de Artillería de Segovia». Revista Storica Italiana, 2015, pp. 211-247. Diccionario biográfico de la Real Academia de la Historia. Voz Tomás Bruno de Morla Pacheco. https://dbe. rah.es/biografias/13338/tomas-bruno-de-morla-pacheco. 
M. ${ }^{a}$ DOLORES HERRERO FERNÁNDEZ-QUESADA

SISTEMAS DE CAPTACIÓN E INNOVACIÓN EN LA FORMACIÓN DEL MILITAR BORBÓNICO...

emblemático en el proceso de formación de la artillería moderna, fueron su nueva organización, la implementación del orden de antigüedad para los ascensos en el Cuerpo, la supresión de la figura del "Cadete de Regimiento" en las unidades artilleras, la consecuente creación de la Compañía de Caballeros Cadetes de Segovia y, por fin, la fundación del Real Colegio de Segovia como única vía de acceso a la oficialidad artillera. Para reglar el sistema de ingreso en el Real Colegio, Gazola agilizó las gestiones para la aprobación de un Reglamento en $1763^{65}$.

De hecho, el conde incluyó la organización en ese mismo Reglamento de nuevo Pie de 1762 de la Compañía de Caballeros Cadetes de Artillería, e hizo todo lo posible, con la ayuda inestimable del ministro Esquilache, para la posterior inauguración el 16 de mayo de 1764 del Real Colegio de Artillería con sede en el Alcázar de Segovia. Con Carlos III y Gazola como autores intelectuales de las llamadas "reformas artilleras" y de la apertura de "su obra predilecta», el colegio segoviano, se trabajó en el marco de un proyecto de Estado articulado en tres planos que interactuaban entre sí, especialmente el segundo con el tercero: la creación del Real Cuerpo; y la fundación del Real Colegio (1762/1764), muy vinculado al tercer plano pues, con oficiales científico-técnicamente formados en la academia, el Estado puso en marcha el tercer objetivo, de gran calado político: la estatalización de la industria militar artillera para que la Corona controlara la producción y el autoabastecimiento, pasando a ser dirigida por oficiales de artillería formados como ingenieros industriales en aquel centro. El Estado empresario militar iba a controlar la industria artillera, incorporar las nuevas tecnologías en el proceso de fabricación, gestionar la producción de las fábricas y garantizarse el autoabastecimiento. Se empezó por las fábricas de cañones de bronces, Sevilla y Barcelona, en buena lógica. El equipo trabajó en ello en tiempo récord a tenor de la rapidez con que se van cubriendo los objetivos. Nuestra hipótesis es que el plan estaba pergeñado antes de viajar, derivado de la etapa napolitana, la experiencia de Gazola y el estudio de la información que llegó a Nápoles desde España en el último año de vida de Fernando VI.

En estos tres planos de actuación Gazola centró su misión, desvelándose sin duda como su pasión la fundación del colegio donde se educarían promociones de artilleros científico-técnica y militarmente, diestros en campaña, pero también como ingenieros industriales para dirigir las fábricas militares. De ahí la importancia de institucionalizar un sistema de enseñanza artillera acertado y eficaz. Pero es necesario destacar aquí el marco intelectual de fondo de este proyecto político-militar, impregnado por el ideario ilustrado del conde a quien parafraseamos cuando al diseñar el Colegio Artillero, convencido de que una buena educación es la base de todo, planteó la arquitectura del colegio militar sobre tres pilares maestros: el mejor claustro de profesores sin cuestionar su origen, especialmente para ocupar

65. Instrucciones que compendiaron las normas y criterios de acceso, cuyo ejemplar manuscrito encontramos rubricado por Carlos III en la Biblioteca de la Academia de Artillería. 
M. ${ }^{a}$ DOLORES HERRERO FERNÁNDEZ-QUESADA

SISTEMAS DE CAPTACIÓN E INNOVACIÓN EN LA FORMACIÓN DEL MILITAR BORBÓNICO...

dos cátedras que Gazola siempre orientó en busca de la excelencia, matemáticas y táctica/artillería, cuyos contenidos se convertirían en los cimientos del nuevo perfil científico-técnico del artillero ilustrado; un completo plan de estudios que rezuma la fundamentación científico-matemática de la artillería, y el cercano fin del basado en la praxis artillera. El artillero debía formarse teóricamente a través de las clases y los libros, del estudio, y después, con esa base ya imprescindible, en la práctica artillera. En la lección inaugural del 16 de mayo de 1764, el jefe de Estudios, padre Eximeno ${ }^{66}$, extractó en su subtítulo el ideario docente de Gazola para el colegio artillero y la formación de los futuros oficiales: «Sobre la necesidad de la teoría para desempeñar en la practica el servicio de SM»; así como el énfasis en aportar los mejores medios para la enseñanza (gabinetes, instrumentos...), pero prioritariamente la formación de una excelente biblioteca en la España de mediados del XVIII como soporte de la docencia e investigación en el colegio. Sin ella el proyecto de formación de nuevos oficiales con perfil científico-técnico habría fracasado.

En la documentación de Simancas encontramos correspondencia sobre los pormenores de la fundación del colegio y leemos declaraciones de intenciones bien explícitas como -en alusión a la formación de la biblioteca del colegiocuando su director afirmaba rotundamente que «no faltarán libros... ni dinero para adquirirlos " ${ }^{67}$. Gazola estaba convencido de ello y de que el núcleo en torno al que se debía desarrollar la vida académica y docente de la academia segoviana era una buena biblioteca, la mejor, y se ocupó personalmente de su dotación con la incorporación de fondos de diversa procedencia y la compra e importación de otros muchos. El ilustrado Gazola bien sabía que sin una biblioteca nutrida y selectamente formada no se conseguirían los objetivos. Esta máxima la cumplió durante todo su mandato al frente del Real Colegio de Artillería y como director que cubrió la etapa fundacional del colegio (1764-1780) 16 años de consolidación. Con esta filosofía y objetivos se fueron llenando los anaqueles de la sala más grande e importante del Alcázar de Segovia. Gracias a los inventarios que se conservan en la Biblioteca de Artillería del Alcázar de Segovia, ya desde su etapa fundacional condensaba la ilustración científica, técnica y militar. El propio conde compraba personalmente, como en el verano de 1769 cuando el conde fue a Italia, pasando previamente por París (donde visitó al ministro Choiseul) y Londres, donde adquirió numerosos libros y publicaciones recientes, así como también algunos tratados como los de Leibnitz y Locke. Gazola regresa a España en septiembre de 1771 con la valija cargada de libros para la biblioteca del colegio. Entre los diferentes gabinetes de apoyo a la enseñanza artillera, la biblioteca del colegio se empezó

66. EXIMENO, Antonio. Oración de apertura de la Real Academia de Caballeros Cadetes del Real Cuerpo de Artillería, 16 de mayo de 1794.

67. Herrero FernándeZ-Quesada, María Dolores. "La innovación militar en el siglo XVIII. Felice Gazzola y el Real Colegio de Artillería de Segovia». Revista Storica Italiana, 2015, pp. 211-247. 
a formar instalándose en la sala de Reyes del Alcázar segoviano ${ }^{68}$. El conocimiento previo ya mencionado por parte del conde de la política borbónica relativa a la institucionalización de la enseñanza militar se demuestra cuando -con conocimiento de causa- reclama fondos específicos de gran valor científico-militar. Concretamente, el punto de partida fueron los fondos de la Academia de Cádiz y de la Real Sociedad Militar de Madrid, más una generosa política de adquisiciones amplia, en muy pocos años se formó una de las mejores bibliotecas científico-militares de la Ilustración española ${ }^{69}$, con la preceptiva autorización de la Inquisición para leer libros prohibidos. El ilustrado Gazola se manifiesta ilustrado en su valoración y respeto al libro como herramienta clave para el conocimiento, y encargó el traslado del bagaje bibliográfico gaditano al capitán Lasso de la Vega porque «ha manejado y conoce el mérito de los espresados libros e Ynstrumentos, y celará que no se deterioren ${ }^{{ }^{70}}$. Del empaque de los fondos bibliográficos nos hablan sus inventarios ${ }^{71}$.

La continuidad en el tiempo, con intermitencias hasta hoy, y los excepcionales planteamientos docentes ilustrados hicieron del colegio un centro de gran prestigio en Europa, a los pocos años de su apertura. Para la artillería sería ya la única vía de acceso a la oficialidad el paso por el colegio, dotado de un plan de estudios al más alto nivel, así como su claustro de profesores y la dotación de infraestructuras para

68. El fondo de partida fueron ejemplares excelentes de la biblioteca de la extinguida escuela de artillería de Cádiz, algunos de ellos adquiridos por Jorge Juan en el extranjero y otros procedentes de la biblioteca de la Real Sociedad Militar Matemática de Madrid. Herrero FERNÁNDEZ-QuesAdA, María Dolores. La enseñanza militar ilustrada. El Real Colegio de Artillería de Segovia. Segovia; BCA, 1990; MARZAL MARTínEZ, Amparo. «Un ejemplo de renovación científica en la Ilustración. La Real Sociedad Militar Matemática de Madrid». Temas de Historia Militar. Actas del Congreso de Historia Militar de Zaragoza, 1982.

69. Herrero FERnÁndeZ-Quesada, María Dolores. «Notas sobre los fondos impresos y documentales de la Biblioteca de la Academia de Artillería y el Archivo Histórico Militar». Estudios Segovianos, número extraordinario homenaje Hilario Sanz. Segovia: Instituto Diego de Colmenares, CSIC, 1996, pp. 349-388, y "El Archivo General Militar de Segovia, decano de los Archivos Militares Españoles». Cuadernos de Historia Moderna, 2012, 38, pp. 165-214.

70. AGS, Guerra Moderna, legajo 560. Aquí se conserva la documentación sobre «la extinción de la Academia de Cádiz y destino de sus efectos para la de Segovia»; así como el "Ymbentario de todos los efectos procedentes de la Real Academia Militar de Mathemáticas que S.M. ha extinguido en la plaza de Cádiz y estaba a cargo del Cuerpo de Artillería». En este mismo legajo se encuentra también la «Relazión de los libros que volvieron de la Academia de Ingenieros de los que existen en la Academia de Barcelona, según el Ymbentario hecho el 20 de diciembre de 1762: los cuales libros se han de remitir a Segovia para el uso de los Caballeros Cadetes». Esta relación estaba fechada el 15 de mayo de 1764 y firmada por Gazola.

71. La biblioteca dependía directamente del jefe de Estudios, según la Ordenanza del Colegio de 1768. Los catálogos que se conservan en la Biblioteca de la Academia de Artillera, cuatro manuscritos de los años 1784, 1790, 1794 y 1796-98, ponen de manifiesto el nivel científico y militar del colegio con una biblioteca que, a finales del siglo XviII, ya superaba los 2300 volúmenes. Por las Actas del Consejo Escolar (ms) se sabe que se invertía anualmente una cantidad importante en compra y reposición. Con la dotación excepcional de aquella biblioteca los profesores del colegio pudieron ejercer la docencia en sus cátedras, pero también investigar y producir textos. 
M. ${ }^{a}$ DOLORES HERRERO FERNÁNDEZ-QUESADA

SISTEMAS DE CAPTACIÓN E INNOVACIÓN EN LA FORMACIÓN DEL MILITAR BORBÓNICO...

la enseñanza, entre las que destaca su magnífica biblioteca científico-técnico-militar y tiempo después el Laboratorio de Química que vino a dirigir Luis Proust. Centro docente, de investigación y con producción propia en lo que se refiere a manuales para la enseñanza, marcando el tránsito de los apuntes manuscritos como metodología al uso del libro de texto. De acuerdo con la política borbónica de dignificación de la oficialidad, se exigieron pruebas de nobleza para ingresar y el ideario docente después determinó el perfil del oficial de artillería ilustrado que dirigía la artillería en campaña, así como las industrias militares españolas y, habitualmente, rebasó el límite de lo castrense para prestar sus conocimientos al servicio de España ${ }^{72}$.

\section{Hacia el Fin de Siglo: ACADEmia de Ávila, Proyectos E inQuietudes PREMONITORIAS}

Este efímero centro de formación militar abulense fue impulsado por el teniente general O'Reilly y ha sido estudiado fundamentalmente por Recio Morales. Los criterios fundacionales del mismo difieren de los anteriores en un aspecto fundamental: era una academia para oficiales y de todas las armas. O'Reilly, que se puso al frente en el ejercicio de la dirección, era en la década de los 70 consciente del decalaje formativo en los perfiles de los oficiales de las armas y los de los Cuerpos Facultativos y los demás (como él mismo). Es por ello que quiso abrir un centro de perfeccionamiento y ampliación de la formación de los oficiales en activo. Por lo tanto, el alumnado que en ella ampliaría su formación militar no estaría formado por bisoños cadetes, sino por oficiales de infantería y caballería de "sobresaliente capacidad para el arte de la guerra", lo que implicaba una selección previa vinculada a las capacidades y perfiles profesionales. La escuela fue dotada con generosidad en cuanto a los medios para la enseñanza, entre los que destaca su importante biblioteca, soporte imprescindible de la formación e investigación para la producción de textos propios para la enseñanza en aquella ciudad $^{73}$, siguiendo, en la implementación de estos planteamientos y en la aportación generosa de medios y gabinetes para la enseñanza, la estela innovadora del Colegio de Artillería. La Academia de Ávila fue un laboratorio experimental pionero, sin duda, en el camino hacia la institucionalización de colegios militares

72. Herrero Fernández-Quesada, María Dolores. «Educando a Marte. Rentabilidad de la innovación docente militar y versatilidad profesional». En HERRERO FERNÁNDEZ-QuesADA, María Dolores (coord.). Entre Marte y Minerva. Los Reales Ejércitos Borbónicos, del reformismo al mito. Cuadernos de Historia Moderna, 2016, 41, 2, pp. 391-424.

73. RECIO MORALEs, Óscar. "Innovación militar en la España del siglo XVIII: la producción científica de la Real Escuela Militar de Ávila (1774)». En HERRERO FERNÁNDEZ-QuESADA, María Dolores (coord.). Entre Marte y Minerva. Los Reales Ejércitos Borbónicos, del reformismo al mito. Cuadernos de Historia Moderna, 2016, 41, 2, pp. 425-442. 
M. ${ }^{a}$ DOLORES HERRERO FERNÁNDEZ-QUESADA

SISTEMAS DE CAPTACIÓN E INNOVACIÓN EN LA FORMACIÓN DEL MILITAR BORBÓNICO...

para todas las armas, más generalistas en los contenidos. De corta vida, como desarrolla Recio en sus trabajos, un quinquenio en el que no se obtuvo la viabilidad y la continuidad que sí tuvieron las academias de los Cuerpos Facultativos de formación para cadetes y muy especializadas científica y técnicamente. Ávila fue una larvada plataforma conceptual que, desarrollada con el paso del tiempo, abrió vías en el largo y lento proceso de formación de colegios generales militares para todos los oficiales de los ejércitos, una realidad ya decimonónica. La existencia de este centro y las investigaciones sobre su corto devenir docente acreditan las inquietudes que siempre presidieron el proceso de innovación en la formación de los militares, siempre en construcción, a lo largo de la centuria, inquietudes que se sustanciaron en proyectos ya en 1802 como el de apertura de colegios militares en Alcalá de Henares, Valladolid y Granada para la educación de los cadetes del ejército ${ }^{74}$.

También con Carlos III, cabe recordar siquiera brevemente el colegio de cirugía de Barcelona. La formación era básica y fundamental para el desempeño del real servicio, y así se entendió para aquellos militares que trabajaban en la Sanidad Militar $^{75}$. En el siglo de la ciencia se abrió este colegio para formar los facultativos necesarios para atender a los reales ejércitos ${ }^{76}$. Junto a las fundaciones efímeras, inquietudes innovadoras que llevaron a proyectos nonatos o de corta vida, pero adelantados a su tiempo en sus planteamientos en el ámbito de la educación para la guerra, podemos señalar aquí, en los años en que Godoy perseguía la autorización real para reorganizar los ejércitos y editar unas nuevas ordenanzas generales, que el ministro mandó fundar una institución pionera y altamente especializada: la Academia de Ingenieros Cosmógrafos militares en 1797. La cosmografía era materia de estudio en los colegios militares, lo atestiguan los planes de estudios y también algunos manuscritos de cadetes que se conservan sobre la materia ${ }^{77}$. El impulso de Godoy a este centro apuntaba la tendencia a la especialización cada vez mayor del militar, ampliando horizontes científicos en la educación de los oficiales. Las ciencias y materias emergentes progresaban por lo que con aquella fundación Godoy apuntaló, en el marco de la innovación en la formación militar, la especialización como eje de la calidad y la excelencia. En este marco se abrió

74. BCM (IHCM), Reglamento que S. M., manda observar en los colegios militares de Alcalá de Henares, Valladolid y Granada para la educación e instrucción de los Cadetes del Exercito. Madrid: Imp. Real, 1802.

75. Herrero Fernández-Quesada, María Dolores. «La ciencia y técnica militar». En VV. AA. Aproximación a la bistoria militar de España. Madrid, 2006, vol. 3.

76. Después, con los mismos objetivos y excelentes resultados, se creó el Colegio de San Carlos en Madrid; así como Aréjula pilotó la creación del Colegio de Cirujía de la Armada.

77. Citaremos dos de los que se conservan en la BCN (IHCM), MS-448. Tratado 6..$^{\circ}$ de la Cosmographía - 1775. [292] pp., [11] h. pleg. de láms. y tablas. Del alumno Carlos Cabrer y Rodríguez; y otro de la misma materia que fue manuscrito y presentado a evaluación por el alumno Félix Colón de Larriategui: Tratado de la cosmografía de la Real Academia de Barcelona, 1773, 239 pp., 9 h. de láms. plegables. MS-1234. 
M. ${ }^{a}$ DOLORES HERRERO FERNÁNDEZ-QUESADA

SISTEMAS DE CAPTACIÓN E INNOVACIÓN EN LA FORMACIÓN DEL MILITAR BORBÓNICO...

este nuevo colegio en el ocaso del siglo que, sin duda, reclama una investigación en profundidad, incardinada con la preocupación por la educación para la guerra y su fundamentación científica en el XVIII ${ }^{78}$.

\section{LA EDUCACIÓN MILITAR A DEBATE: LA VOZ DE UN CONTEMPORÁNEO, JOSÉ CADALSO, MILITAR Y ESCRITOR}

El debate profesional sobre el sistema de enseñanza militar en la Ilustración fue recurrente dentro de la institución, pero traspasando las lindes de lo castrense, también en los círculos sociales, y consecuencia de su interés aparece presente en la literatura, como tema y trama en una obra de José Cadalso. En este artículo junto a las aportaciones de las fuentes primarias, para finalizar, cobra interés dar voz a un contemporáneo, escritor pero también militar -conocedor de la institución y su intrahistoria en el XVIII-, que se hace eco de la opinión sobre el tema de la educación militar, pasándolo por el filtro de la sátira y la ironía, distorsionadoras, pero que utiliza para poner sobre el tapete literario las luces y sombras del modelo de formación de oficiales. Un sistema educativo desigual, que no solo debía proporcionar réditos en el campo de Marte, sino que también debía visibilizarse en sociedad como paradigma de una exitosa política de progreso en este ámbito, patente en la escena pública a través de una cuidada representación en los espacios de sociabilidad. Cadalso construye su obra sobre una estructura docente y articula en siete lecciones de un capitán a sus alumnos, aspirantes a ser militares "a la violeta». Por su perfil profesional como militar y por su formación en el ámbito de las letras, tiene voz un contemporáneo, quien en su obra y desde la sátira aporta intangibles y matices difíciles de detectar en la documentación, además de opinión. La opinión autorizada de un militar con criterio, hombre de su siglo ${ }^{79}$ que, en la penúltima década y tras los Eruditos, se atrevió con un opúsculo dedicado a los militares, muy centrado en la formación de los oficiales dieciochescos y su proyección en los espacios de sociabilidad, y en la construcción de una imagen apriorísticamente determinada que persiguió la nueva Monarquía. Con este raro impreso, por difícil de encontrar, El buen militar a la violeta ${ }^{80}$, abrimos las reflexiones y análisis de este artículo al testimonio de un protagonista y a la vez

78. Ordenanzas del Cuerpo de Ingenieros Cosmógrafos del Estado y del Real Observatorio. Madrid: Imprenta Real, 1796. Una vez creado el Cuerpo, al año siguiente, 1797, se fundó la Academia.

79. José Cadalso fue un hombre de su tiempo, como se aprecia en el estudio de su biografía personal y profesional que ratifica que nos encontramos ante un militar ilustrado. HERrERO FERNÁNDeZ-Quesada, María Dolores y Álvarez Barrientos, Joaquín. "Estudio Preliminar». En Cadalso, José. Lecciones a la violeta. Madrid: Sýstole, 2010, pp. 15-49.

80. CADAlSO, José. El buen militar a la violeta. Lección Posthuma del autor del Tratado de los Eruditos. Sevilla: Imprenta Mayor de la ciudad, 1790, p. VII. En adelante los entrecomillados corresponden a este texto y omitiremos las notas reiteradas. Una obra reciente es la de PESET, José Luis. Melancolía e Ilustración. Diálogos cervantinos en torno a Cadalso. Madrid: Abada, 2015. 
espectador en tiempo real que, desde la fina ironía, vuelca en su obra percepciones necesarias y desmitificadoras para el análisis poliédrico del modelo docente militar borbónico, sus éxitos y fracasos. Cadalso ${ }^{81}$ viajó y estudió en Europa, y a su vuelta se matriculó en el Seminario de Nobles de Madrid para continuar con su educación, volviendo después a Londres y París. Tras el fallecimiento de su padre en Copenhague, estrenando la década de los 20, según refleja su Hoja de Servicios $^{82}$, ingresó en los Reales Ejércitos, como Cadete de Cuerpo en el Regimiento de Caballería de Borbón. En sus Cartas Marruecas hace una referencia descriptiva del cadete dieciochesco, enfatizando su origen social nobiliario, que decide ingresar en una unidad "haciendo siempre el servicio de soldado raso; y después de haberse portado como es regular se arguya de su nacimiento, es promovido al honor de llevar una bandera con las armas del rey y divisa del regimiento" ${ }^{83}$. En este sentido, cabe señalar -siguiendo a Andújar- ${ }^{84}$ que la línea ideológica contradictoria de la Ilustración española se refleja especialmente en el militar del XVIII, aserto que cuadra perfectamente con la biografía personal y profesional de Cadalso, de origen noble con vocación militar que tiene dificultad en sostener la coherencia, por la transversalidad de sus actividades literarias ${ }^{85}$.

Lo primero que pone de manifiesto este autor en su obra es la diferencia de instrucción de los oficiales, según su generación, con diferencias sustanciales entre $s i^{86}$. A Cadalso habría que encuadrarlo en la generación de 1760, y se constata en los escritos del militar gaditano ese choque generacional con los predecesores, la crítica intergeneracional, dos modelos militares enfrentados en su concepción institucional de los ejércitos, y en el perfil de su oficialidad, marcado por su instrucción. El debate sobre la más adecuada organización de los ejércitos siempre estuvo servido y hoy asistimos a una revisión historiográfica desmitificadora; y la

81. Desde su nacimiento en la ciudad de Cádiz -tempranamente privado de la presencia de sus padres (conoció a su padre a los 13 años)-, su educación quedó en manos de un tío materno, jesuita, el padre Mateo Vázquez, que determinó las bases de su formación al estudiar en los colegios de la orden, en Cádiz y París. El joven Cadalso estudió fuera de España y viajó por la Europa ilustrada, lo que condicionó la estructura de su mente y su formación integral y cosmopolita, sustanciada en el dominio de cuatro lenguas aparte del español y las muertas.

82. AGS, Guerra Moderna, legajo 966. Hoja de Servicios de José Cadalso y Vázquez.

83. Cadalso, José. Cartas marruecas. Madrid, 1979. Resume así el criterio de captación del servicio de las armas planteado como un honor reservado a la nobleza, como un logro de la política de captación y formación de los nuevos oficiales del xviII.

84. ANDújar Castillo, Francisco. Los militares en la España del siglo XVIII. Un estudio social. Granada: Universidad de Granada, 1991.

85. Cadalso hace sus reconocidas críticas que nunca alcanzarán, sin embargo, a la nobleza que estaba nutriendo los Reales Ejércitos de nuevos y jóvenes oficiales nacidos y educados como correspondía a sus casas. Así, curiosamente, el origen social privilegiado de los militares ilustrados españoles nunca fue satirizado en sus escritos, no era "casus belli» ni objeto de crítica, muy al contrario, se asumía desde dentro como natural.

86. Algunos autores efectivamente determinan la existencia de varias generaciones de militares en el XVIII. GAY ARMENTERos, Juan. La Ilustración andaluza. Granada, 2008. 
M. ${ }^{a}$ DOLORES HERRERO FERNÁNDEZ-QUESADA

SISTEMAS DE CAPTACIÓN E INNOVACIÓN EN LA FORMACIÓN DEL MILITAR BORBÓNICO...

crítica al sistema educativo castrense se presentaba trufada en la discusión ${ }^{87}$. En su Hoja de Servicios, destacaremos su destino en Madrid que le proporcionó contactos y amistades, su capital relacional ${ }^{88}$ (clave en la interactuación de las élites), teniendo trato frecuente con figuras como el conde de Aranda, probablemente el militar que Cadalso más admiró. Como oficial ilustrado no quiso perderse una de las grandes acciones militares de la época: el "Gran Sitio» de Gibraltar ${ }^{89}$, donde perdió la vida. Su fallecimiento dejó inédito El buen militar que no fue impreso hasta 1790 en Sevilla. Este retraso es posible que algo tuviera que ver con la censura. Esta circunstancia y que no haya habido reediciones posteriores hace que sea una de sus obras menos accesibles y también menos conocidas por el gran público.

\subsection{El buen militar a la violeta}

Cadalso escribió sus "violetos" sobre dos colectivos cerrados y endogámicos, los eruditos o intelectuales y los militares. En el segundo caso, nos encontramos ante una institución jerarquizada que se sustentaba sobre uno de sus valores más señeros, la disciplina, que excluía la opinión y la crítica. Cadalso aunó estas dos profesiones y, con información de primera mano, pudo articular sus obras. Sobre la misma estructura literaria de los Eruditos, El buen militar se plantea en un entorno pedagógico como una carta más de un discípulo violeto, un capitán a su catedrático Joseph Vázquez, seudónimo utilizado por Cadalso ${ }^{90}$. Está fechada en Pafos, isla de Chipre, el 1 de diciembre de $1772^{91}$. Posiblemente, Cadalso se dejase un poco a sí mismo en el retrato de ese capitán que escribe a su maestro en violetismo ${ }^{22}$. En El buen militar hay una continuidad con los Eruditos, tanto formal

87. Herrero Fernández-Quesada, María Dolores (coord.). Entre Marte y Minerva. Los Reales Ejércitos Borbónicos, del reformismo al mito. Cuadernos de Historia Moderna, 2016, 41, 2; CEPEDA GÓmEZ, José. "La buena prensa de los Ejércitos Borbónicos. Una mirada crítica». En HERRERO FERNÁNDEZ-QuESADA, María Dolores (coord.). Entre Marte y Minerva. Los Reales Ejércitos Borbónicos, del reformismo al mito. Cuadernos de Historia Moderna, 2016, 41, 2.

88. Imízcoz Beunza, José María. «El capital relacional: relaciones privilegiadas y redes de influencias en el Estado español del siglo XviIı. En Imízcoz Beunza, José María y Oliveri KorTa, Olihane. Economía doméstica y redes sociales en el Antiguo Régimen. Madrid: Silex, 2010, pp. $227-282$.

89. Prueba de ello es su inquietud dentro de la profesión que le llevó a diseñar un plan para el sitio y toma de Gibraltar. Esta operación militar se trata en HERRERO FERNÁNDEZ-QueSADA, María Dolores. Ciencia y milicia en el siglo XVIII. Tomás de Morla, artillero ilustrado. Segovia: PAS, 1992.

90. Aguilar PIÑal, Francisco. Bibliografía de autores españoles del siglo XVIII. Madrid: CSIC, 1981-1986. 4 vols.

91. Autores como Luis Alberto de Cuenca se han preguntado sobre el porqué de su exclusión del corpus del Suplemento, especulando con que quizá Cadalso no lo hubiera redactado aún, o que su extensión sobrepasara los límites exigidos a un folleto por el editor.

92. Sobre la valoración de la obra literaria de Cadalso, la opinión sobre su obra de Sempere y Guarinos era que los Eruditos son «una sátira ingeniosa y muy bien escrita contra cierta clase de gentes que aparentan saber mucho, habiendo estudiado poco». SEMPERE y GuARINOS, Juan. Ensayo de una biblioteca española de los mejores escritores del reinado de Carlos III. Madrid: Imprenta Real, 1787. 6 volúmenes. 
y de estilo como temática. Además, este opúsculo ha resultado ser un delicioso compendio de los usos sociales de los militares españoles del XVIII, dirigido y dedicado a ellos; enfatizando los aspectos relacionados con su educación; articulándolo pedagógicamente en lecciones, que conforman casi un manual, el decálogo de El buen militar...; la hoja de ruta del oficial dieciochesco que quiere escalar en su carrera, y las normas para tener un comportamiento social impecable, casi canónico, para moverse en sociedad con solvencia, representando el papel profesional y social asignado, proyectando la imagen que todos esperaban de él, pero siempre haciendo gala de su formación militar. ¿Cadalso, un pionero del coaching contemporáneo? El militar debía serlo, pero también parecerlo, y en la obra se refleja con ironía y sentido del humor el perfil social y público del oficial de su tiempo. Las lecciones de El buen militar son en un compendio de normas básicas de cumplimiento inexcusable para el militar dieciochesco fuera de la institución militar. Cadalso estructuró, sin duda a modo de divertimento, siete lecciones para gestionar la imagen pública del oficial en sociedad.

El XVIII fue un siglo cosmopolita definido por la comunicación, también oral, de ahí el auge de las tertulias y reuniones literarias, y, para Cadalso, el militar violeto era "carne de tertulia». En El buen militar, y esto tiene particular interés, dibujó el perfil del militar que la sociedad demandaba en aquel momento, y la proyección de su imagen en los salones y foros sociales diversos acordes con las expectativas creadas, lo que pasaba por hacer ostentación de una formación epatante. Desde el punto de exageración que permite la sátira, en esta pequeña obra se encuentra perfectamente descrita la tipología de los militares violetos, más que visibles socialmente. Lejos de la táctica o de las armas, el capitán a la violeta aparece como asesor profesional y de imagen de la juventud militar que tendrá que representar su papel en sociedad tal y como retrata en su escrito dirigido a quien consideraba una autoridad en el tema, don Joseph Vázquez, catedrático a la violeta, el máximo rango, y autor de lo que denomina el "Curso de Erudición a la Violeta, con que Vmd sirve al Público», estructurado en esas lecciones que contenían «lo que corresponde a cada cual en la Sociedad. Tan solo tras siete lecciones, una por día de la semana. ¿Frivolización y licencia literaria?, ¿reflejo en clave irónica de un estado de opinión desde dentro de la institución militar en tiempo real?, ¿ingenio y divertimento transgresor de un militar escritor? Las reformas políticas y militares se estructuraron y muchas funcionaron, resultando por lo general exitosas las relativas a la educación para la guerra. La campaña de marketing parece que dio resultados, pero Cadalso raspó sobre la pátina luminosa de la apariencia, poniendo el contrapunto a la heredada percepción social de la milicia, anticuada, basada en principios que -a su entender- chirriaban en "un siglo tan civilizado como el nuestro", por lo que como punto de partida de su obra, para utilidad práctica del colectivo, decidió «sujetar todos los principios de la Teórica Militar al suave y útil 
imperio de la moda ${ }^{93}$. Esta declaración de intenciones que encontramos al principio de la obra es clave para interpretar El buen militar. La moda manda y obliga a una actualización de los militares dieciochescos en su contexto social, llegando a entender el coronel Cadalso que «no sería justo privar a la mejor porción del Estado, y al más bello adorno de la sociedad, de la gloria y comodidad que le resultará de conseguir tan útiles y fáciles conocimientos...». El autor reflejó en su sátira, hilvanada con ironía pero con criterios utilitaristas, una guía básica para los militares que debían salir de los cuarteles al ruedo social. Por ello, desarrolla su discurso desde el momento en que el militar se calza el uniforme, su primera seña de identidad, su icono identificativo en sociedad, por lo que en El buen militar se dará importancia al cuidado del uniforme hasta el más nimio de los detalles, especialmente porque, además, servía para distinguir al militar del "golilla»" detallando incluso hasta el último complemento de la uniformidad reglamentaria, desde relojes a colonias o perfumes ${ }^{95}$. El retrato del militar violeto continúa con una exhaustiva descripción de comportamientos, desde los cotidianos con la propia tropa hasta las actitudes en espacios sociales ${ }^{96}$. Ahondando en la provocación, sobre los colegios militares que, en la época de Cadalso, se encontraban en las cosmopolitas ciudades de Cádiz y Barcelona de las que salieron promociones de excelentes oficiales de los Cuerpo Facultativos, el autor también banaliza, asegurando que los jóvenes militares acudían con otros objetivos: "Todo brillante joven ha empleado algunos años en las disipaciones que ofrecen las plazas de Barcelona y Cádiz, con el pretexto de estudiar las Matemáticas... contribuyendo el nombre de buen matemático para el ascenso...». Argumento claramente desmitificador de Cadalso con respecto a la imagen del oficial ilustrado que pasaba en su formación por centros académicos, posiblemente hijo de la rivalidad entre la oficialidad mayoritaria y los minoritarios oficiales de las armas sabias que se intuía en la documentación oficial,

93. CADAlso, José. El buen militar a la Violeta. Lección Posthuma del autor del Tratado de los Eurditos. Sevilla: Imprenta Mayor de la ciudad, 1790, p. VII. En adelante los entrecomillados corresponden a este texto y omitiremos las notas reiteradas.

94. Evidenciando el enfrentamiento de poder y social entre estos dos colectivos en pugna en el ecuador del XVIII. El corporativismo institucional y el enconamiento entre ambos partidos rezuma cuando Cadalso se refiere a los "gafetes" del uniforme que el militar "por ningún acontecimiento llamará Corchetes, por ser cosa que huele a Golillas, perpetuos enemigos nuestros".

95. Y es precisamente también en las recomendaciones para el cuidado del uniforme donde ya se pone de manifiesto el choque generacional (que ya se observó en los Eruditos... entre los viejos literatos y los violetos). Desde la apariencia física, la forma de vestir el uniforme salta a la vista la confrontación, la diferencia entre los viejos militares y los jóvenes oficiales, con un nuevo perfil muy determinado por la época que les tocó vivir, por los gustos y, sin duda, por la moda, partidarios de los «adornos y la pulcritud" frente a lo que Cadalso calificaba como "desaliñados Veteranos», sin duda menos preocupados por su aspecto, y cuidada sin embargo hasta el extremo por las nuevas generaciones.

96. Esto podría llevar a la percepción de una aparente frivolización de la profesión militar en el opúsculo satírico de los militares violetos, extrapolable a los textos dedicados al asunto de nuestro interés, tan relevante para la Monarquía como lo fue la formación y educación de los oficiales. 
aquí se constata ¿menos interés científico-militar del que se presumía y más gusto por lo lúdico y por frecuentar los espacios de sociabilidad del XVIII, cuyo estudio es tendencia en la historiografía modernista más contemporánea? ${ }^{97}$.

En este proceso de disección exprés de la imagen del militar violeto, Cadalso compiló recomendaciones variopintas que serían de utilidad al joven oficial para la correcta percepción de su imagen pública. Se trataba no solo de ser militar, sino de parecerlo y con fundamento, las apariencias había que cuidarlas para proyectar una imagen canónica del oficial, indicando como conveniente, por ejemplo, «reunir planos y levantamientos topográficos o perfiles de las más importantes plazas fortificadas» y copiarlos personalmente o que lo parezca para «sostener mejor la ilusión» social. Es particularmente revelador el capítulo de consejos que debían seguir también en su espacio más íntimo, en las habitaciones que ocupaban ocasionalmente como las de una posada, sujetas a los ojos de los demás, en las que todo debía ajustarse al guion violeto, proponiendo incluso cómo debía ser y estar su mesa de trabajo, donde siempre tendría desplegado un mapa geográfico, un "estuche matemático", planos inconclusos y, lo fundamental, "todo amontonado y confuso, como que manifiesta haberse separado de la mesa fatigado del trabajo, y sin ánimo para dexar ordenados los papeles, pues toda esta, aunque comunísima impostura, produce favorables efectos, haciendo creer a los ignorantes mucho ingenio y aplicación...». Esta cuidada puesta en escena no coincide en absoluto con lo investigado, por ejemplo, sobre los ingenieros militares españoles y su proyección profesional, sus potentes obras de fortificación en los territorios de la Monarquía. En la transgresión textual de su obra, Cadalso frivolizó con las recomendaciones para proyectar una imagen que no ofrezca lugar a dudas adornada de dos virtudes imprescindibles para un militar del XVIII, ingenio y aplicación. Y ya fuera del ámbito profesional y del espacio más privado, el militar saldrá a las "tertulias y concurrencias" haciendo ostentación de su formación elitista. El maestro de violetos comenzaría estudiando a los asistentes a sus clases, teniendo cuidado de que no estén presentes ni viejos oficiales (más sabios) ni canónigos o frailes. Sin elementos opacantes en el horizonte, se sugiere que el oficial centre

97. Dedieu, Jean-Pierre; Castellano, Juan Luis y López-Cordón, María Victoria. La pluma, la mitra y la espada: estudios de historia institucional en la Edad Moderna. Madrid: Marcial Pons, 2000; Imízcoz Beunza, José María. Élites, poder y red social: las élites del País Vasco y Navarra en la Edad Moderna (estado de la cuestión y perspectivas). Universidad del País Vasco, 1996; "Élites administrativas, redes cortesanas y captación de recursos en la construcción social del Estado Moderno". Trocadero: Revista de Historia Moderna y Contemporánea, 2007, 19, pp. 11-30; "Familia y redes sociales en la España Moderna». En LORENZO PINAR, Francisco Javier. La familia en la historia. Salamanca: Universidad de Salamanca, 2009, pp. 135-186; o "Actores sociales y redes de relaciones: reflexiones para una historia global». En Imízcoz BeunzA, José María. Redes familiares y patronazgo: aproximación al entramado social del País Vasco y Navarra en el Antiguo Régimen (siglos XV-XIX). Universidad del País Vasco, 2001, pp. 19-30; Herrero FERnÁndeZ-Quesada, María Dolores. "La formación de los militares en el siglo XVIII. El Colegio Artillero de Segovia o la creación de un modelo». En Imízcoz Beunza, José María y CHAPARRO, Álvaro (eds.). Educación, redes y producción de élites en el siglo XVIII. Madrid: Sílex, 2013, pp. 317-336. 
su intervención con desparpajo en «el estado político de la Europa» en general, intentando epatar con su conocimiento sobre los ejércitos extranjeros, aportando datos rigurosos en apariencia para su "lucimiento", se trataba de aparentar dominio y solvencia tanto en la formación como en la información. De hecho, su discurso en aquellos foros no tenía que estar basado en lecturas de los tratados militares y políticos actualizados. El Capitán Violeto aseguraba sin rubor que el militar articularía su argumentación «de lo que haya pillado por el pico en las conversaciones de los Oficiales Veteranos...». Confusa contradicción. El final de aquellas intervenciones en sociedad terminaría siempre con un corolario, una sentencia clara y obligada, al modo: "Señores, no hay para qué cansarnos, que es forzoso que confesemos, que nuestra España va siempre un siglo atrasada con respecto a las Naciones más cultas de Europa, en todas las ciencias y las artes, y que hasta el presente no se sabía qué cosa era disciplina militar, infatuados con nuestras antiguas conquistas, debidas más al capricho de la fortuna que al conocimiento del arte de la guerra...». Silencio y fin. Junto a este relato discursivo, el Capitán Violeto daba recomendaciones posturales que ayudasen a la teatralización del papel de buen militar: "Y luego, haciendo una profunda cortesía hacia todas partes baxando la cabeza, y levantando los hombros con el cuerpo inclinado, y marchando de puntillas se saldrá de la concurrencia...", incorporando el lenguaje no verbal que ya era herramienta en los espacios de sociabilidad. Una obra, por tanto, de gran actualidad que nos presenta la mejor versión de Cadalso como intelectual, crítico, pionero y adelantado a su época con mucho. Por lo que respecta a la asistencia de actos culturales como representaciones teatrales, el Capitán Violeto aportaba pautas de comportamiento con la concurrencia, y con respecto a las damas en particular, acabando al final de la pieza siempre con un «bravo, bravo, bonisimo» ${ }^{88}$.

El militar violeto, en la crítica al pasado de la institución militar, es demoledor, y va más allá del choque generacional. Se enfrentan dos conceptos de milicia y de guerra, dos modelos de ejércitos bien distintos. Los militares violetos eran la renovación esperanzada de una institución que algunos presentaban como anclada aún en la gloria de los tercios y los antiguos capitanes. Sobre el ejercicio de la profesión, cada vez más compleja y tecnificada, los violetos defenderían con pasión que estos asuntos fueran llevados únicamente por los militares; quejándose siempre de falta de dotación económica por la Real Hacienda, un clásico intemporal. Para el final del opúsculo, el Capitán Violeto dejó lo que hoy llamaríamos los "libros de cabecera" del buen militar, lecturas obligadas, desde Voltaire a clásicas españolas como la Celestina, y algún breviario religioso para cubrir las apariencias, con especial protagonismo para las militares, propias de su educación castrense y,

98. Estas apariciones públicas y sus intervenciones siempre tenían que desarrollarse en condiciones que no perjudicasen a su honor y, en caso contrario, no había otra vía que la del desafío ineludible. 
sobre todo, las no recomendadas ${ }^{99}$. Cadalso escribió un compendio desde la provocación y el humor, dando especial protagonismo a las apariencias para los militares violetos, suficientes para cubrir objetivos como se desprende del corolario de tan delicioso texto: "Así conseguiréis la gracia de las Damas, el aplauso de los Caballeros, la admiración de todos, y en fin llegar al término que apeteceis a merced de la comodísima, y florida disciplina de la Violeta». El coronel deja entrever la dualidad ideológica y social en la que se desenvolvieron los militares ilustrados que - para Andújar- es exponente perfecto de las contradicciones internas del reformismo ilustrado ${ }^{100}$, presentando en El buen militar un perfil de oficial inquieto, que se mueve en los límites que le permite esa contradicción intelectual, siempre abocado a posturas más reformistas que rupturistas. El debate entre el pasado y el presente ¿acertado? de la milicia estuvo sobre el tapete durante todo el XVIII, tenemos múltiples testimonios documentales centrados en el nuevo modelo de formación de oficiales que nos ocupa. En nuestra opinión, Cadalso lo recoge en sus Cartas, o Eruditos, pero con mayor claridad en El buen militar a la violeta ${ }^{101}$. Su voz y opinión nos llegan a través del Capitán a la Violeta como profesor que, además, se presenta en modo asesor de imagen de la juventud militar como retrata en su escrito dirigido a quien consideraba una autoridad en el tema, don Joseph Vázquez, catedrático a la Violeta, el máximo rango, y autor de lo que denomina el "Curso de Erudición a la Violeta, con que Vmd sirve al Público", con lecciones que compendian "lo que corresponde a cada cual en la Sociedad». De lo recogido en su Hoja de Servicios, cabe destacar su destino en Madrid que, sin duda, le proporcionó ese nivel de relaciones y amistades, el capital relacional ${ }^{102}$ (clave en la interactuación de las élites), que le llevó a tener trato frecuente con figuras como el conde de Aranda, probablemente el militar que Cadalso más admiró. Es posible que a finales de la centuria reflejara la opinión de algunos escépticos con respecto al modelo educativo cuando enfatizaba hasta casi el esperpento las

99. Entre estas encontramos una buena parte de tratadística militar clásica, que basaba el arte militar en el conocimiento empírico y no en el científico como en el siglo ilustrado; desaconsejaba la lectura de los antaño grandes tratados que jalonan la historia de la literatura militar «que solo contienen instrucciones sacadas de propias experiencias y observaciones inútiles en un siglo tan ilustrado como el que vivimos, en el que un bisoño soldado sale de su casa con más instrucción y teórica militar que tenía el famoso Rui-Díaz, después de haber ganado a Valencia». Herrero Fernández-Quesada, María Dolores y Álvarez Barrientos, Joaquín. «Estudio Preliminar». En Cadalso, José. Lecciones a la violeta. Madrid: Sýstole, 2010, pp. 15-49.

100. ANDÚJAR CASTILLO, Francisco. Los militares en la España del siglo XVIII. Un estudio social. Granada: Universidad de Granada, 1991; Herrero FERnándeZ-QuesAda, María Dolores y Álvarez BARRIENTOS, Joaquín. «Estudio Preliminar». En CADALSO, José. Lecciones a la violeta. Madrid: Sýstole, 2010.

101. Cadalso, José. El buen militar a la violeta. Lección Posthuma del autor del tratado de los eruditos. Sevilla: Imprenta Mayor de la ciudad, 1790.

102. ImízCOZ BEUNZA, José María. «El capital racional: relaciones privilegiadas y redes de influencias en el Estado español del siglo XVIII». En Imízcoz BeunZA, José María y Oliveri KorTA, Olihane. Economía doméstica y redes sociales en el Antiguo Régimen. Madrid: Sílex, 2010, pp. 227-282. 
M. ${ }^{a}$ DOLORES HERRERO FERNÁNDEZ-QUESADA

SISTEMAS DE CAPTACIÓN E INNOVACIÓN EN LA FORMACIÓN DEL MILITAR BORBÓNICO...

representaciones y puestas en escena social del militar violeto ${ }^{103}$. Pero no podemos olvidar que en oficiales de los Cuerpos Facultativos esa excelencia científico-técnica en su formación no era apariencia, era real, acreditada y reconocida por otros militares de mejor o peor grado, como Cadalso, quien en su opúsculo se permitió un desahogo tintado de rencor profesional, el pulso que inmemorialmente ha existido entre armas y los cuerpos. Sin duda, nadie más lejos del petimetre que los oficiales de artillería e ingenieros, de tal manera que no nos resistimos a reproducir la mordaz expresión que acuñó Cadalso para hacer referencia a la solvente y densa educación de los artilleros, que calificó como «erudición morteril»104, erudición sí, pero pesada como los morteros, piezas de artillería de entidad.

\section{CONCLUSIONES}

En el proceso de captación social y definición del sistema de educación militar de los Borbones en el XVIII, se transitó entre la gloria y el mito del anterior con los tercios como icono en el imaginario español hasta la institucionalización de una formación de mayor carga científico-técnica y especialización para los militares profesionales. La arquitectura del nuevo modelo de educación estuvo en construcción durante toda la centuria, sujeta a revisiones e innovaciones experimentales que marcaron ya el futuro. Coexistieron dos modelos para educar para la guerra a los cadetes, en los regimientos o en los colegios militares, según su adscripción a armas o cuerpos. En su análisis colegimos que fue un sistema de formación desigual para oficiales promovidos con niveles de instrucción muy diferentes, de ahí que los resultados de sus trayectorias profesionales también lo fueran en el servicio del rey, siendo prevalentes en utilidad los ingenieros militares y los artilleros. En este estudio cronológicamente y por reinados evocamos la evolución de ambos sistemas de instrucción y la progresiva innovación docente militar cifrada en nuevos proyectos: unos que presentan una consolidación de larga duración, como la Academia de Barcelona y el Colegio de Segovia; otros de efímera trayectoria, la Real Sociedad Matemática de Madrid, y algunos pergeñando ya centros para la formación académica de todos los oficiales de los ejércitos (Academia Militar de Avila), señalando premonitoriamente el camino aún lejano hacia la conceptualización de colegios generales militares, en la misma línea que los colegios de Alcalá de Henares, Valladolid y Granada. Y, finalmente, inquietudes sustanciadas en proyectos y fundaciones que acreditan a finales de siglo la tendencia prevalente hacia la especialización científico-técnica como la creación del Cuerpo y después la Academia de

103. Cadalso, José. Ibid., p. XII.

104. Esta expresión se incluye en su obra más conocida sobre los violetos. CADALSO, José. Los eruditos a la violeta o curso completo de todas las ciencias dividido en siete lecciones para los siete dias de la semana, compuesto por José Vázquez, quien lo publica en obsequio de los que pretenden saber mucho, estudiando poco. Madrid: Imprenta A. Sancha, 1782, p. 111. 
Ingenieros Cosmógrafos militares. La documentación oficial, desde la de la Secretaría del Despacho a la generada por los diferentes centros, sus directores, claustros de profesores y alumnos con proyección profesional notable, es clave para el análisis a final de siglo del modelo docente militar implementado. A pesar del claroscuro que presentan algunas academias y centros de corta vida y recorrido, entre el ya cuestionado mito de las exitosas reformas militares borbónicas que han presentado fallas y evidente soslayo silente del cumplimiento de las ordenanzas, es justo reconocer que los colegios militares más consolidados, Guardiamarinas de Cádiz, Matemáticas de Barcelona y Real Colegio de Artillería de Segovia, suman de forma contundente en el haber de la política de la educación para la guerra de la nueva dinastía.

Pero estas fuentes también aportan, de forma más dispersa, testimonios personales impagables para la ponderación del balance final. Para el caso de los ingenieros y la artillería es patente. La Academia de Ingenieros de Barcelona y el colegio de artillería tuvieron un protagonismo especialmente relevante en el ámbito castrense, pero igualmente en el científico, de la Ilustración, escribiendo páginas imprescindibles de la historia de la ciencia y la técnica en España, porque,como hace años se puso de manifiesto en un estudio ya clásico y pionero, "los científicos del XVIII vistieron uniforme militar en buena parte» ${ }^{105}$. En este sentido, integramos en este artículo y en sus conclusiones el caso del centro segoviano investigado en trabajos previos, que se convirtió en paradigma de colegio militar ilustrado, ascendiendo exponencialmente en las sucesivas décadas a unas cotas que lo reconocen como el ejemplo más perfecto de la innovación docente militar del XVIII español, con continuidad en el XIX y Xx, y que conserva su sede segoviana fundacional, después de 256 años ${ }^{106}$, su anejo Real Laboratorio de Química dirigido por Luis Proust; la adquisición de la colección de minerales de Casimiro Gómez Ortega; el alto nivel en química metalúrgica o en pirotécnica, imprescindibles para asumir las riendas directivas de la naciente industria militar estatalizada desde Carlos III; y la trayectoria de los oficiales allí formados confirman la línea ascendente del colegio, que rebasa la frontera del siglo y acredita su continuidad en el XIX.

105. CAPEl SÁEZ, Horacio; SÁNCHEZ, Joan Eugeni y MONCADA, Omar. De Palas a Minerva La formación científica y la estructura institucional de los ingenieros militares en el siglo XVIII. Madrid: Serbal, 1988.

106. HERRERO FERNÁNDEZ-QueSADA, María Dolores. "La innovación militar en el siglo XVIII. Felice Gazzola y el Real Colegio de Artillería de Segovia». Revista Storica Italiana, 2015, pp. 211-147; "La formación de los militares en el siglo XVIII. El Colegio Artillero de Segovia o la creación de un modelo». En Imízcoz Beunza, José María y Chaparro, Álvaro (eds.). Educación, redes y producción de élites en el siglo XVIII. Madrid: Sílex, 2013, pp. 317-336; Herrero FERnÁNDEZ-QueSADA, María Dolores. "El Real Colegio de Artillería. De la fundación a la consolidación de un modelo de centro docente militar y científico-técnico». Revista Historia Militar. 250 aniversario del Real Colegio de Artillería. Instituto de Historia y Cultura Militar, 2014, 58, 1, pp. 73-133. 
M. ${ }^{a}$ DOLORES HERRERO FERNÁNDEZ-QUESADA

El XVIII se inició con el nuevo sistema de reclutamiento de la oficialidad en los ejércitos borbónicos de la Nueva Planta Militar, con los requisitos o condiciones de ingreso. Las expectativas optimistas a medida que avanzaba el siglo se volatilizaron como consecuencia de la desigualdad ya aludida, que resultó ser letal para el modelo, que entró en crisis a finales del XVIII en el marco de la crisis del ejército borbónico y de la crisis generalizada que anunciaba el fin del Antiguo Régimen. Aún O'Reilly buscó paliar las carencias formativas de los oficiales de las armas, como él mismo, en centros docentes de educación comunes como la escuela de Ávila. Godoy fue más allá, intentó la reorganización del modelo militar que llevaba implícita la del sistema de formación, incidiendo en la importancia de la especialización promoviendo centros como el de Ingenieros Cosmógrafos militares. A modo de balance, parece claro que el reformismo militar borbónico no consiguió para la mayoría de los militares la mejor versión del oficial que habría pasado por la institucionalización de la enseñanza militar para todas las armas y cuerpos. La conciencia política se tenía, los mandos militares igualmente lo habían asumido en el eterno debate de su formación, pero la economía política no se podía permitir este enorme apunte contable al total del gasto militar de la Monarquía. Sin embargo, y en la columna del haber, sí que ganaron la batalla de la imagen, de la valoración y percepción social de la milicia, encontrando la oficialidad, como élite, un lugar social y en los círculos de poder. Es más, el modelo de educación militar fue asunto político de envergadura encuadrado en el proyecto de Estado destinado a la formación y operatividad de unos ejércitos permanentes y objeto de debate social. Hubo aciertos y desaciertos, intentos frustrados, proyectos educativos para la milicia tan de corta vida como interesantes en sus planteamientos, a pesar de lo cual el debate sobre la enseñanza militar siempre estuvo ahí, y el núcleo de la discusión estaba sin duda en la bondad del sistema de formación de cuadros de mando ${ }^{107}$. El eco del debate social se ha incorporado a nuestro estudio, al dar voz a un contemporáneo, el militar y escritor José Cadalso que en su satírica obra $E l$ buen militar a la violeta... y sobre estructura literaria disecciona las luces y sombras de la educación del militar ilustrado. Las lecciones aportan a esta investigación histórica matices, percepciones, intangibles y opinión de los contemporáneos en tiempo real con la que, lejos de la información oficial, cerramos el círculo del estado de la cuestión sobre el modelo de educación para la guerra por el que se optó en los ejércitos borbónicos.

\section{Bibliografía}

AndúJar Castillo, Francisco. "La educación de los militares en la España del siglo XVIII". Chronica Nova, 1991, 19, pp. 245-276.

107. Andújar CASTILlo, Francisco. "La educación de los militares en la España del siglo XVIII». Chronica Nova, 1991, 19, pp. 245-276. 
Andújar Castillo, Francisco. "El fuero militar en el siglo XVIII. Un estatuto de privilegio". Chronica Nova, 1996, 23, pp. 11-31.

AndúJar Castillo, Francisco. «El Seminario de Nobles de Madrid en el siglo XVIII. Un estudio social». Cuadernos de Historia Moderna, Anejos, 2004, 3, pp. 201-225.

CADALSO, José. El buen militar a la Violeta. Lección Posthuma del autor del Tratado de los Eruditos. Sevilla: Imprenta Mayor de la ciudad, 1790.

Calvo Maturana, Antonio. "La oficialidad del ejército y la marina borbónicos: reformismo, fidelidad e identidad (1750-1808)». En Herrero FERnÁNDEZ-QuesadA, María Dolores (coord.). Entre Marte y Minerva. Los Reales Ejércitos Borbónicos, del reformismo al mito. Cuadernos de Historia Moderna, 2016, 41, 2, pp. 467-495.

Capel SÁez, Horacio; SÁnchez, Joan Eugeni y Moncada, Omar. De Palas a Minerva: la formación científica y la estructura institucional de los ingenieros militares en el siglo XVIII. Madrid: CSIC, 1988.

CEPEDA GÓmEz, José. «Servir al Rey y servir a la nación: ilustrados, liberales y el deber militar». Cuadernos de Historia Moderna, 1995, 16, pp. 139-146.

CEPEDA Gómez, José. "La buena prensa de los Ejércitos Borbónicos. Una mirada crítica». En Herrero FernándeZ-Quesada, María Dolores (coord.). Entre Marte y Minerva. Los Reales Ejércitos Borbónicos, del reformismo al mito. Cuadernos de Historia Moderna, 2016, 41, 2, pp. 355-371.

Chaparro SAINZ, Álvaro. "La formación de las élites ilustradas vascas: el Real Seminario de Vergara». En Imízcoz Beunza, José María y Chaparro, Álvaro (eds.). Educación, redes y producción de élites en el siglo XVIII. Madrid: Sílex, 2013, pp. 157-176.

Clonard, Conde de. Memoria histórica de las Escuelas Militares, 1847.

Dedieu, Jean-Pierre; CASTellano, Juan Luis y López-Cordón, María Victoria. La pluma, la mitra y la espada: estudios de historia institucional en la Edad Moderna. Madrid: Marcial Pons, 2000.

Eximeno, Antonio. Oración de apertura de la Real Academia de Caballeros Cadetes del Real Cuerpo de Artillería, 16 de mayo de 1764.

FERnÁNDEZ DE MEDRANo, Sebastián. Memorias militares en que solo se trata del manejo de la Artillería, sus diferencias, conocimientos de metales y refuerzos, y puntos más convenientes para la práctica, uso y advertencia de los artilleros. Madrid: Imprenta Mateo Espinosa y Arteaga, 1671.

FERNÁNDEZ DE MEDRANO, Sebastián. El práctico artillero que contiene tres tratados. Bruselas: Imprenta Francisco Foppens, 1680.

FERnÁNDEZ De MEDRANO, Sebastián. El arquitecto perfecto en el arte militar. Amberes: Imprenta Henrico y Cornelio Verdussen, 1708.

Galland-Seguela, Martine. Le ingenieurs militaires espagnols de 1710 à 1803. Étude prosopographique et sociale d'un corps d'élite. Tesis doctoral. École des Hautes Études en Sciences Sociales. Director Bernard Vincent. Paris, 2003.

Galland-Seguela, Martine. "Las condiciones materiales de la vida privada de los ingenieros militares en España durante el siglo XVIII. Scripta Nova: Revista Electrónica de Geografía y Ciencias Sociales, 2004, 8, pp. 157-180.

García HurTado, Manuel Reyes. «Formación militar de infantería y caballería en las academias del XVIII». En Imízcoz BeunZA, José María y Chaparro, Álvaro (eds.). Educación, redes y producción de élites en el siglo XVIII. Madrid: Sílex, 2013, pp. 347-371.

Gay Armenteros, Juan. La Ilustración andaluza. Granada, 2008. 
M. ${ }^{a}$ DOLORES HERRERO FERNÁNDEZ-QUESADA

SISTEMAS DE CAPTACIÓN E INNOVACIÓN EN LA FORMACIÓN DEL MILITAR BORBÓNICO...

Herrero Fernández-Quesada, María Dolores. Catálogo de la Biblioteca del Real Colegio de Artillería de Segovia. Fondos artilleros y de fortificación. Segovia: Academia de Artillería de Segovia, 1992.

Herrero Fernández-Quesada, María Dolores. Ciencia y milicia en el siglo XVIII. Tomás de Morla, artillero ilustrado. Segovia: PAS, 1992.

Herrero Fernández-QueSADA, María Dolores. «Consideraciones en torno a la enseñanza artillera en el siglo XVIII. La proyección científico-técnica de los artilleros». En GIMÉNEZ, Enrique y Balaguer, Emilio (eds.). Actas del Congreso Ejército, Ciencia y Sociedad en la España del Antiguo Régimen. Alicante: Instituto de Cultura Juan Gil-Albert, 1995, pp. 407-433.

Herrero Fernández-Quesada, María Dolores. «Notas sobre los fondos impresos y documentales de la Biblioteca de la Academia de Artillería y el Archivo Histórico Militar». Estudios Segovianos, número extraordinario homenaje Hilario Sanz. Segovia: Instituto Diego de Colmenares, CSIC, 1996, pp. 349-388.

HerRero FERnÁndeZ-Quesada, María Dolores. «La ciencia y técnica militar». En VV. AA. Aproximación a la historia militar de España. Madrid, 2006, vol. 3.

HERRERO FERNÁNDEZ-QueSADA, María Dolores. «La investigación en historia militar de la Edad Moderna y sus fuentes. El Archivo General Militar de Segovia, Decano de los archivos militares españoles». Cuadernos de Historia Moderna, 2012, 38, pp. 165-214.

HERRERO FERNÁNDEZ QuESADA, María Dolores. «El nuevo modelo de ejército en el contexto de la Guerra de Sucesión Española». En GARCía GARCíA, Bernardo (coord.). En nombre de la paz. La Guerra de Sucesión Española y los Tratados de Madrid, Utrecht, Rastatt y Baden. 1713-1715. Madrid: Fundación Carlos de Amberes-SECC, 2013, pp. 91-106.

HERRERO FERNÁNDEZ-QueSADA, María Dolores. «La formación de los militares en el siglo XVIII. El Colegio Artillero de Segovia o la creación de un modelo». En Imízcoz Beunza, José María y CHAPARRO, Álvaro (eds.). Educación, redes y producción de élites en el siglo XVIII. Madrid: Sílex, 2013, pp. 317-336.

HerRero FERnÁndez-Quesada, María Dolores. «El Real Colegio de Artillería. De la fundación a la consolidación de un modelo de centro docente militar y científico-técnico". Revista Historia Militar. 250 aniversario del Real Colegio de Artillería. Instituto de Historia y Cultura Militar, 2014, 58, 1, pp. 73-133.

HERRERO FERNÁNDEZ-QueSADA, María Dolores. «La innovación militar en el siglo XVIII. Felice Gazzola y el Real Colegio de Artillería de Segovia». Revista Storica Italiana, 2015, pp. 211-247.

HERRERO FERNÁNDEZ-QueSADA, María Dolores (coord.). Entre Marte y Minerva. Los Reales Ejércitos Borbónicos, del reformismo al mito. Cuadernos de Historia Moderna, 2016, $41,2$.

HerRero FernándeZ-Quesada, María Dolores. «Educando a Marte. Rentabilidad de la innovación docente militar y versatilidad profesional». En HERRERO FERNÁNDEZ-QueSADA, María Dolores (coord.). Entre Marte y Minerva. Los Reales Ejércitos Borbónicos, del reformismo al mito. Cuadernos de Historia Moderna, 2016, 41, 2, pp. 391-424.

Herrero Fernández-Quesada, María Dolores. «¿Una aguja en un pajar? En torno a un caso de divorcio en los archivos militares». En Hernández SANDOICA, Elena. Espacio público y espacio privado, miradas desde el sexo y el género. Madrid: Abada, 2016, pp. 319-356.

HERRERO FERNÁNDEZ-QueSADA, María Dolores. «Matrimonio con militar. Procedimientos, excepciones a la norma y contenciosos a finales del Antiguo Régimen». En CAPEL MARTíneZ, Rosa María. La voz de las mujeres en el espacio público (siglos XVII-XX). Madrid: Abada, 2019. 
Imízcoz BeunZA, José María. «El capital racional: relaciones privilegiadas y redes de influencias en el Estado español del siglo XVIII». En Imízcoz BeunZA, José María y Oliveri KORTA, Olihane. Economía doméstica y redes sociales en el Antiguo Régimen. Madrid: Silex, 2010, pp. 227-282.

Imízcoz BeunZa, José María y Chaparro, Álvaro (eds.). Educación, redes y producción de élites en el siglo XVIII. Madrid: Sílex, 2013.

Lucuze, Pedro. Principios de Fortificación. Barcelona: Thomas Piferrer, 1772.

MARZAl MARTínez, Amparo. «Un ejemplo de renovación científica en la Ilustración. La Real Sociedad Militar Matemática de Madrid». Temas de Historia Militar. Actas del Congreso de Historia Militar de Zaragoza, 1982.

Molas Ribalta, Pere y Segovia Barrientos, Francisco (coords.). La Academia de Matemáticas de Barcelona. El legado de los Ingenieros Militares 1720-1803. Barcelona: Museu Marítim de Barcelona, 2004.

Peset, José Luis. Melancolía e Ilustración. Diálogos cervantinos en torno a Cadalso. Madrid: Abada, 2015.

PeSeT, José Luis y LAFuente, Antonio. «Las Academias militares y la invasión en ciencia en la España Ilustrada». Dynamis, 1982.

PORTUGues, Joshep Antonio. Colección de Ordenanzas militares, sus innovaciones y aditamentos, dispuestos en diez tomos, con separación de clases. Madrid: Imprenta de Antonio Marín, 1764.

RABANAL Yus, Aurora. «El tratado de arquitectura enseñado en la Real y Militar Academia de Matemáticas de Barcelona». Anuario del Departamento de Historia y Teoría del Arte, 1990, 2, pp. 179-185.

RECIO MORALES, Óscar. «Innovación militar en la España del siglo XVIII: la producción científica de la Real Escuela Militar de Ávila (1774)». En Herrero FERNÁNDEZ-Quesada, María Dolores (coord.). Entre Marte y Minerva. Los Reales Ejércitos Borbónicos, del reformismo al mito. Cuadernos de Historia Moderna, 2016, 41, 2, pp. 425-442.

RODRíguez HERnÁNDEZ, Antonio José. «El ejército que heredó Felipe V: su número y su composición humana». En BernARDo ARES, José Manuel de (coord.). La sucesión de la Monarquía Hispánica, 1665-1725. Córdoba: Universidad de Córdoba, 2009, pp. 265-301.

ROdríguez Hernández, Antonio José. «Evolución o innovación? Los cambios técnico-tácticos en el armamento del ejército español durante el relevo dinástico: nuevas consideraciones». En HerRero FernáNDEZ-QueSADA, María Dolores (coord.). Entre Marte y Minerva. Los Reales Ejércitos Borbónicos, del reformismo al mito. Cuadernos de Historia Moderna, 2016, 41, 2, pp. 273-294.

Rodríguez Villa, Antonio. Noticia biográfica de Don Sebastián Fernández de Medrano (1646-1705). Madrid, 1885.

SEMPERE y GUARINOS, Juan. Ensayo de una biblioteca española de los mejores escritores del reinado de Carlos III. Madrid: Imprenta Real, 1787. 6 volúmenes.

Vigón Suero-Díaz, Jorge. Historia de la Artillería Española. Madrid: CSIC, 1947. 3 tomos. 